\title{
Elementos de tierras raras disueltos en agua subterránea y su relación con los sistemas de flujo en rocas marinas y volcánicas en el Bajío de Guanajuato, Centro de México
}

\section{Tatiana Salinas-Reyes y M. Adrián Ortega-Guerrero*}

\author{
Centro de Geociencias, Universidad Nacional Autónoma de México, \\ Campus UNAM Juriquilla, Blvd. Juriquilla no. 3001, C.P. 76230, Querétaro, Qro., México. \\ *maog@geociencias.unam.mx
}

\section{RESUMEN}

Se utilizan Elementos de Tierras Raras (ETR) - serie de los lantánidos - disueltos en agua subterránea para determinar su interacción con medios granulares y fracturados en dos provincias geológicas en el centro de México: la Mesa Central (MC) y la Faja Volcánica Transmexicana (FVTM). Se obtuvieron 94 muestras de agua subterránea en el suroeste del Estado de Guanajuato, en las que se determinó la concentración de ETR. Se utilizó el programa geoquímico PHREEQC para simular la especiación acuosa y obtener los índices de saturación con respecto a fases minerales y mezclas de agua. Los resultados muestran que las anomalías de cerio $(\mathrm{Ce})$ y europio $(\mathrm{Eu})$ son características de los procesos de la interacción agua-roca: las anomalías negativas de Ce se asocian a las aguas subterráneas que circulan en un acuífero carbonatado-marino del Cretácico, y las anomalías negativas y positivas de Eu se asocian a acuíferos fracturados de la MC y FVTM, respectivamente. Los ETR se incorporan al agua subterránea por la disolución de minerales presentes en las rocas y su concentración es controlada por el $\mathrm{pH}$, la coprecipitación y los procesos de sorción. La presencia de anomalías negativas de Ce, en los acuíferos fracturado y granular superyacientes al acuífero carbonatado, sugieren continuidad hidráulica entre ellos a través de fallas y micro-fracturas conectadas a profundidades mayores a $1000 \mathrm{~m}$. Este comportamiento es consistente con el modelo Gravitacional de Sistemas de Flujo de Agua Subterránea (SFAS) Tóthiano-Freezeano, en donde los ETR actúan como trazadores naturales en la definición del flujo regional en este medio geológico complejo, confirmando la importancia de considerar los tiempos de residencia y la componente vertical de los SFAS en la gestión del agua subterránea.

Palabras clave: lantánidos; elementos traza; Sistemas de Flujo de Agua Subterránea; Guanajuato; Acuífero del Bajío.

\begin{abstract}
Rare Earth Elements (REE) - series of lanthanides - were used to determine the water-rock interaction process in two geological provinces in central Mexico: the Mesa Central (MC) and the Trans-Mexican Volcanic Belt (FVTM). Ninety-four groundwater samples were collected from fractured and granular aquifers in the southwestern part of the State of Guanajuato, from which REE concentrations were analytically
\end{abstract}

determined in all of the samples. The geochemical software PHREEQC was later used to determine aqueous speciation, saturation indices with respect to mineral phases and mixing. The results show that the anomalies of cerium (Ce) and europium (Eu) are characteristic in the determination of water-rock interactions. The negative anomalies of Ce are associated with groundwater circulating through a carbonated-marine Cretaceous aquifer; whereas the negative and positive anomalies of the Eu are associated to fractured aquifers of MC and FVTM. The REE are incorporated into the groundwater by dissolution of minerals present in the rocks and their concentration is controlled by $\mathrm{pH}$, coprecipitation and sorption processes. The presence of negative anomalies of $\mathrm{Ce}$, in the fractured and granular aquifers above the carbonated aquifer, suggests an hydraulic continuity between them through faults and fractures connected to depths greater than $1000 \mathrm{~m}$. This behavior is consistent with the Gravitational model of Groundwater Flow Systems (GFS) TóthianFreezean, so the REEs act as natural tracers in defining the regional flow in this complex geological environment and confirming the importance of considering the residence time and vertical components of GFS in groundwater management.

Key words: lanthanides; trace elements; groundwater flow systems; Guanajuato; Bajío aquifer.

\section{INTRODUCCIÓN}

Los Elementos de Tierras Raras (ETR) son ampliamente usados como indicadores geoquímicos en determinados procesos geológicos (Henderson, 1984), entre los que destacan: la petrogénesis de rocas ígneas (Orozco-Esquivel et al., 2002; Gómez-Tuena et al., 2007; Winter, 2014), el estudio de ambientes de depósito de rocas sedimentarias (Murray et al., 1990), el seguimiento de procesos geoquímicos que ocurren en el océano tales como reacciones reducción-oxidación, mezcla de diferentes masas de agua y ciclos, así como en la determinación y tiempos de residencia de metales y partículas suspendidas (Goldberg et al., 1963; De Baar et al., 1985; Sholkovitz et al., 1994), entre muchos otros procesos. Recientemente, los ETR disueltos en agua subterránea han sido utilizados como trazadores de flujo, indicadores de conectividad hidráulica entre unidades geológicas, análisis de mezclas y la respectiva contribución de miembros extremos de agua subterránea (Smedley, 1991; Johannesson et al., 1997; Banks et al., 1999; Tweed

Salinas-Reyes, T., Ortega-Guerrero, M.A., 2019, Elementos de tierras raras disueltos en agua subterránea y su relación con los sistemas de flujo en rocas marinas y volcánicas en el Bajío de Guanajuato, Centro de México: Revista Mexicana de Ciencias Geológicas, v. 36, núm. 1, p. 125-145. 
et al., 2006; Biddau et al., 2009; Siebert et al., 2012; Yan et al., 2013). Estas características hacen a los ETR importantes en la determinación de los Sistemas de Flujo de Agua Subterránea (SFAS) y en la gestión de acuíferos (Freeze y Witherpoon, 1966, 1967, 1968; Tóth, 1999). Con el fin de explorar diferentes aspectos de los sistemas de flujo de agua subterránea y su interacción con las rocas por las que circulan, en el presente trabajo se reportan resultados de concentraciones de ETR de 94 muestras de agua subterránea del suroeste de Guanajuato (Ortega-Guerrero, 2000) y la integración de la concentración de ETR en rocas volcánicas que dominan en la Mesa Central y la Faja Volcánica Transmexicana.

\section{DESCRIPCIÓN DEL ÁREA DE ESTUDIO}

La zona de estudio corresponde a la región IV Sur-Oeste de Guanajuato y abarca un área de aproximadamente $4600 \mathrm{~km}^{2}$ según el Consejo Regional para el Desarrollo del Estado de Guanajuato (IPLANEG, 2014); comprende los municipios de Cuerámaro, Manuel Doblado, Abasolo, Huanímaro, Pénjamo, Pueblo Nuevo y Valle de Santiago (Figura 1a).

\section{Geología}

La zona de estudio está localizada en el límite de dos provincias fisiográficas: la Mesa Central (MC) al norte y la Faja Volcánica Transmexicana (FVTM) al sur, separadas por la Falla del Bajío, de desplazamiento normal y que da lugar a la depresión del mismo nombre (Nieto-Samaniego et al., 2007) (Figura 1a). A su vez, en la región se puede observar la transición espacio-temporal de la actividad volcánica de la Sierra Madre Occidental (SMOcc) con la FVTM, generada por la reorganización del esquema tectónico del arco del Pacífico durante el Mioceno temprano; esta transición trae consigo un marcado cambio composicional de los magmas félsicos de la SMOcc al predominio de los basaltos y andesitas efusivos de la FVTM (Ferrari et al., 1999; Cerca et al., 2000).

La Mesa Central, ubicada entre las provincias fisiográficas de la Sierra Madre Occidental y la Sierra Madre Oriental (SMO), corresponde a un altiplano cuya elevación promedio, de $2250 \mathrm{msnm}$, supera y contrasta con la de sus alrededores, que son menores a 1800 msnm (Nieto-Samaniego et al., 1997; Nieto-Samaniego et al., 2007). Localmente, en la Sierra de Guanajuato en el extremo meridional de la Mesa Central, afloran las unidades litológicas más antiguas de la zona de estudio (Figura 2), conformadas por rocas marinas del Jurásico Tardío al Cretácico Temprano que se consideran como parte del Terreno Guerrero (Alaníz-Álvarez et al., 2001; Aranda-Gómez et al., 2003; Nieto-Samaniego et al., 2007). Rocas continentales cenozoicas, tanto volcánicas como de cuencas fluviales-lacustres y depósitos aluviales, cubren discordantemente a las rocas mesozoicas y conforman la mayor parte de los afloramientos en la zona de estudio (Nieto-Samaniego et al., 2007; SGM, 1997). Próximo al límite con la FVTM, predominan las ignimbritas y riolitas del Oligoceno (Aranda-Gómez et al., 2003; Nieto-Samaniego et al., 2007; Aguillón-Robles et al., 2009) cuyo origen se atribuye al vulcanismo de la SMOcc (Aranda-Gómez et al., 2003).

La SMOcc es el arco volcánico del Cretácico Tardío al Mioceno temprano generado durante la subducción de la Placa Farallón bajo la Placa de Norteamérica. La parte basal corresponde a un complejo plutónico-volcánico que se emplazó hasta el Eoceno (Figura 1a). La secuencia superior, del Eoceno al Mioceno medio, comprende aproximadamente 1000 metros de espesor de rocas volcánicas silícicas que afloran a lo largo de una franja de cerca de $1200 \mathrm{~km}$ de largo y $300 \mathrm{~km}$ de ancho que corre paralela a la costa del océano Pacífico de México (Cerca et al., 2000).
La FVTM es el arco volcánico actual que atraviesa el país desde el Golfo de México hasta el norte de Puerto Vallarta, Jalisco, con una orientación aproximada E-W. Este arco fue generado por la subducción de las placas Cocos y Rivera bajo la placa de Norteamérica desde el Mioceno temprano (Figura 1a; Gómez-Tuena et al., 2007; Ferrari et al., 2012).

En la zona de estudio, el vulcanismo de la SMOcc se caracteriza por ser de carácter silícico, compuesto de ignimbritas y domos riolíticos del Oligoceno al Mioceno temprano, mientras que la secuencia de la FVTM está conformada principalmente por intercalaciones de flujos de basaltos y andesitas del Mioceno medio al Plioceno tardío (Figura 2; Cerca et al., 2000; Aranda-Gómez et al., 2003; Ferrari, 2003; Ferrari et al., 2012). Depósitos sedimentarios fluviales-lacustres y aluviales del Oligoceno al Cuaternario rellenan los bajos topográficos, generalmente asociados a fosas tectónicas de la zona, denominadas como el Bajío de Guanajuato (Ferrari et al., 1994; Aranda-Gómez et al., 2003; SGM, 1997; Botero-Santa et al., 2015).

\section{Hidrogeología}

En la zona de interés convergen dos sistemas principales de agua subterránea, uno proveniente de Celaya-Salamanca-Irapuato, en sentido E-W (CONAGUA, 2002), y otro de León-Silao-Irapuato en sentido N-S (Salas, 2009), lo cual podría tener fuertes implicaciones en la presencia y comportamiento hidrogeoquímico de los ETR en el agua subterránea de la región.

La zona de estudio está comprendida dentro de los denominados acuíferos administrativos de Pénjamo-Abasolo y Río Turbio, y parcialmente en los acuíferos administrativos de Irapuato-Valle y La Muralla (CEAG, 2001). La explotación de estos acuíferos empezó en la década de 1970 a través de pozos de entre 80 y 120 metros de profundidad, donde el agua era extraída principalmente de sedimentos lacustres. A pesar de la veda instaurada en la década de 1980 para evitar el bombeo excesivo del acuífero, éste presenta un alto grado de abatimiento de los niveles piezométricos (CEAG, 2001); el estudio citado contiene adicionalmente información litológica, hidráulica e hidrogeoquímica.

De acuerdo a la naturaleza geológica de la conductividad hidráulica de los materiales, se reconocen dos tipos de acuífero en la zona de estudio: uno de carácter granular y otro fracturado (Hernández-Laloth, 1991; CEAG, 2001; Ortega-Guerrero, 2000). El acuífero granular corresponde a todo el material continental que se encuentra rellenando las fosas tectónicas, es decir, a los depósitos fluviales-lacustres que se han depositado desde el Oligoceno tardío y a los materiales granulares cuaternarios que se encuentran al tope de la secuencia. HernándezLaloth (1991) estimó una conductividad hidráulica de $2.3 \times 10^{-5} \mathrm{~m} / \mathrm{s}$ para esta unidad a partir de pruebas de bombeo y caudal especifico versus transmisividad en el Valle de León, ubicado al norte del área de estudio.

El acuífero fracturado está conformado por unidades volcánicas de la SMOcc que presentan un alto grado de fracturamiento, fundamentalmente ignimbritas y riolitas del Oligoceno, aunque también se incluyen algunos flujos de lava andesítica-basáltica del Mioceno tardío que se encuentran intensamente fracturados. Una conductividad hidráulica de $1 \times 10^{-5} \mathrm{~m} / \mathrm{s}$ fue estimada para la Ignimbrita Cuatralba en el Valle de León (Hernández-Laloth, 1991), unidad correlacionable con las ignimbritas oligocénicas fracturadas de la zona de estudio.

A pesar de la falta de información hidráulica de las rocas de la secuencia vulcano-sedimentaria mesozoica, la CEAG (2001) las define como el basamento hidrogeológico, lo cual resulta lógico si se considera la deformación a las que han sido sometidas. Sin embargo, como se verá más adelante, los patrones de ETR normalizados al Promedio Mundial de Lutita (WSA, por sus siglas en inglés) evidencian que hay flujo de agua subterránea a través de las calizas mesozoicas. Por esta 


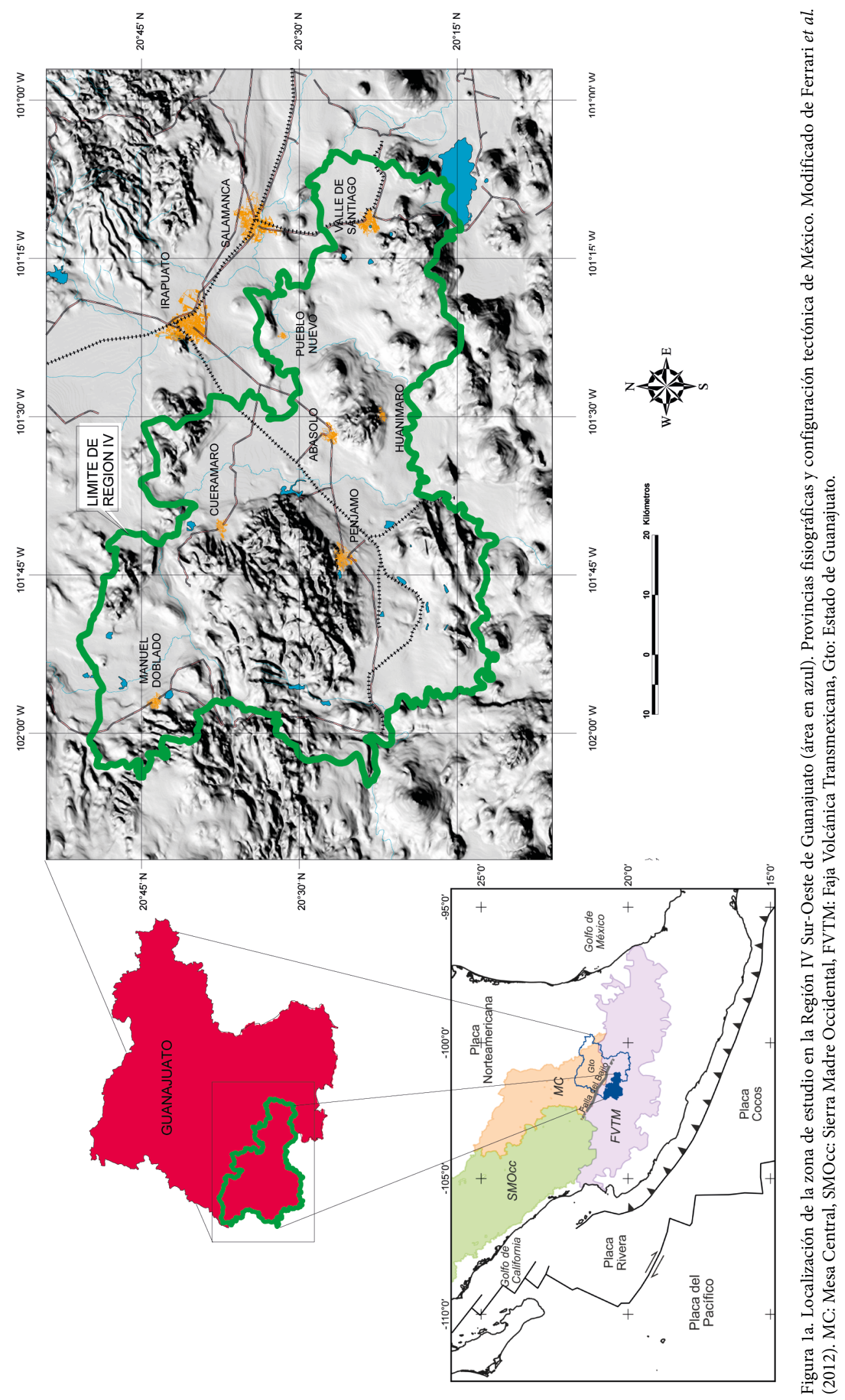




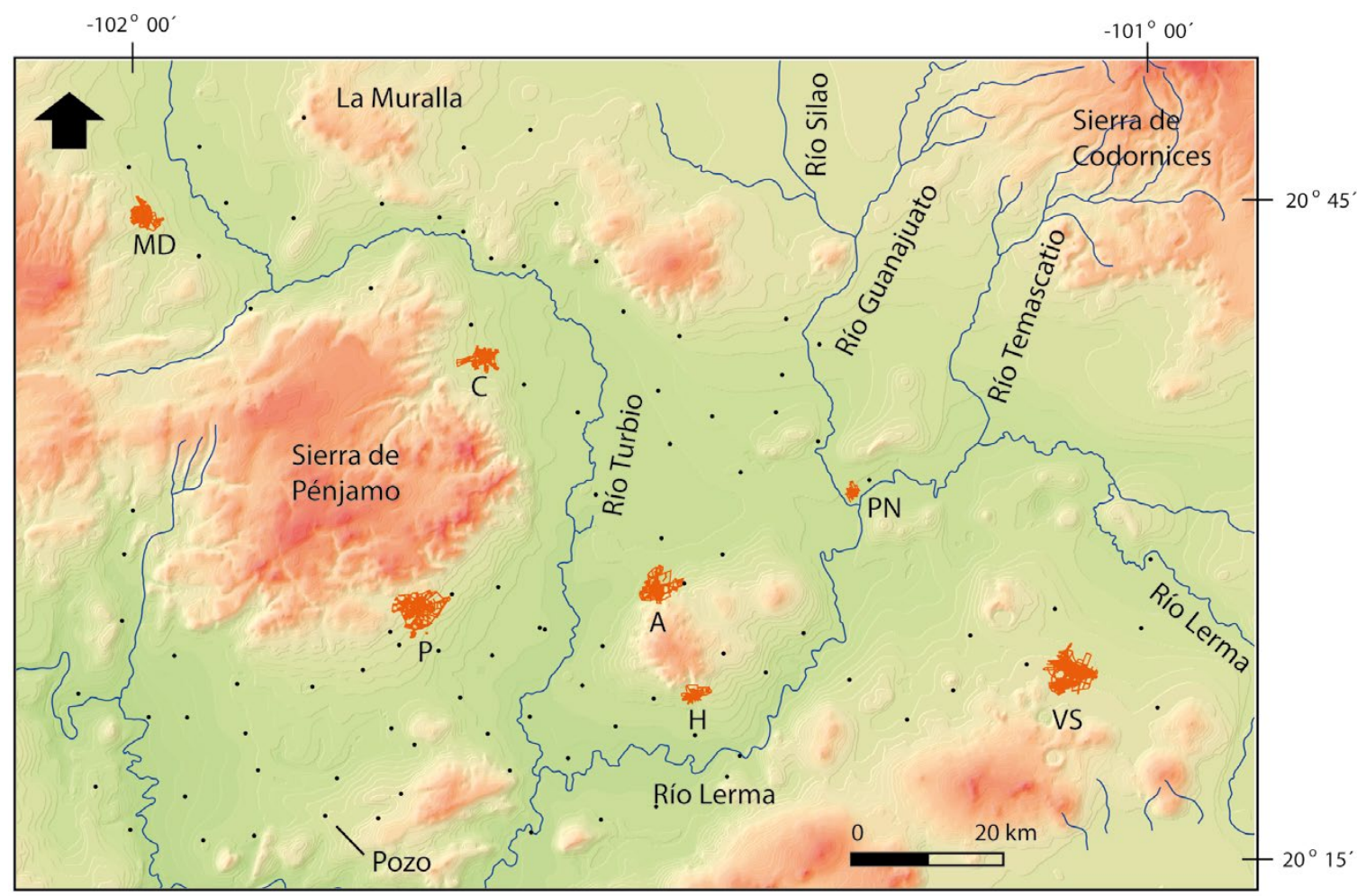

Figura 1b. Ubicación de los 94 sitios de muestreo de agua subterránea en el área de estudio. También se muestran los ríos, sierras y ciudades principales: A: Abasolo, C: Cuerámaro, H: Huanímaro, MD: Manuel Doblado, P: Pénjamo, PN: Pueblo Nuevo y VS: Valle de Santiago.

razón, aunque con una conductividad hidráulica menor respecto a los acuíferos ya mencionados, las rocas marinas de la secuencia vulcanosedimentaria, por lo menos las calizas, también pueden ser consideradas como parte del sistema de flujo de agua subterránea. Los flujos basálticos compactos y capas delgadas de material arcilloso cenozoico de baja conductividad hidráulica se encuentran intercalados en la secuencia, separando los grandes espesores de materiales de mayor conductividad hidráulica (CEAG, 2001).

\section{METODOLOGÍA}

En el año 2000 se recolectaron 94 muestras de agua subterránea en 91 pozos, dos norias y un manantial de la zona de estudio, cuya ubicación se muestra en la Figura 1 b (Ortega-Guerrero, 2000). Las muestras se colectaron, al menos, dos horas después de iniciado el bombeo. Los parámetros físico-químicos de temperatura, $\mathrm{pH}$ y conductividad eléctrica fueron medidos en campo usando un medidor portátil marca Conductronic, modelo PC18 (precisión de $\mathrm{pH}: \pm 0.02$, conductividad: de \pm 1 a $1.5 \%$, temperatura: $\pm 1^{\circ} \mathrm{C}$, exactitud de $\mathrm{pH}: 0.01$, conductividad (según el rango): $0.1,1 \mu \mathrm{S}$ y $0.01 \mathrm{mS}$, temperatura: $0.1^{\circ} \mathrm{C}$ ). El instrumento fue calibrado con buffers de 5, 7 y 10 para el caso del potencial de hidrogeno $(\mathrm{pH})$, y con una solución de concentración conocida de $\mathrm{KCl}$ para la conductividad eléctrica. La alcalinidad también se midió in situ en alícuotas de $200 \mathrm{ml}$ filtradas a $0.45 \mu \mathrm{m}$ mediante titulación con soluciones de $0.1 \mathrm{~N}$ y $1 \mathrm{~N}$ de $\mathrm{HCl}$.

Las botellas de muestreo, de polietileno de baja densidad, doble tapa y $125 \mathrm{ml}$ de capacidad, fueron previamente lavadas con una solución diluida de HCL y, finalmente, con agua destilada. Dos tipos de muestras fueron colectadas para cada sitio, una para análisis de cationes y elementos traza filtradas con una malla $0.45 \mu \mathrm{m}$, y la otra para análisis de aniones. Las muestras destinadas al análisis de cationes y elementos traza, fueron acidificadas hasta un $\mathrm{pH}$ de 2 mediante la adición de $\mathrm{HNO}_{3}$ de alta pureza. Una vez llenadas las botellas, fueron selladas con parafilm y almacenadas en hielo durante su traslado. Las muestras se mantuvieron refrigeradas a $4{ }^{\circ} \mathrm{C}$ hasta su traslado al laboratorio "Activation Laboratories Ltd." (Actlabs) en Canadá, con certificación internacional, en donde se efectuaron los análisis químicos, en un periodo de una semana. Las muestras fueron analizadas con las técnicas de espectrometría de masas, con plasma inductivamente acoplado (ICP-MS) y cromatografía iónica (IC). El control de calidad, por parte del laboratorio, incluyó el análisis del material de referencia certificado (NIST 1643 D). Los análisis de los ETR, se determinaron con el equipo ELAN 6000 ICP-MS cuadrupolar, usando calibración externa y el material de referencia SLRS-4. Controles adicionales fueron la consideración de blancos y la repetición de los análisis en seis de las muestras.

Las concentraciones de ETR en muestras de roca se recopilaron a partir de información existente de la FVTM (Ferrari et al., 2012) y de la SMOcc (Orozco-Esquivel et al., 2002); el programa estadístico R (R Core Team, 2013) fue utilizado para seleccionar muestras representativas. Adicionalmente, y con el fin de confirmar la concentración de ETR en rocas del área de estudio, se colectaron dos muestras de ignimbrita de la SMOcc en la Sierra de Pénjamo (Figura 1b): la primera, en las proximidades de la población de Corralejo (ToIg-01C), y la segunda, en una cañada cercana a la Zona Arqueológica de Plazuelas (ToIg-02P). Las dos muestras fueron analizadas en su contenido de elementos traza y ETR, por medio de ICP-MS en el Centro de Geociencias de la UNAM, con la preparación y análisis según Mori et al. (2007). Las concentraciones promedio de ETR en las rocas fueron normalizadas con respecto al estándar Condrita (Sun y McDonough, 1989), mientras que, las concentraciones de ETR en agua subterránea y las concentraciones promedio de ETR en rocas fueron normalizadas con respecto al Promedio Mundial de Lutita (Piper, 1974). En el primer caso se 


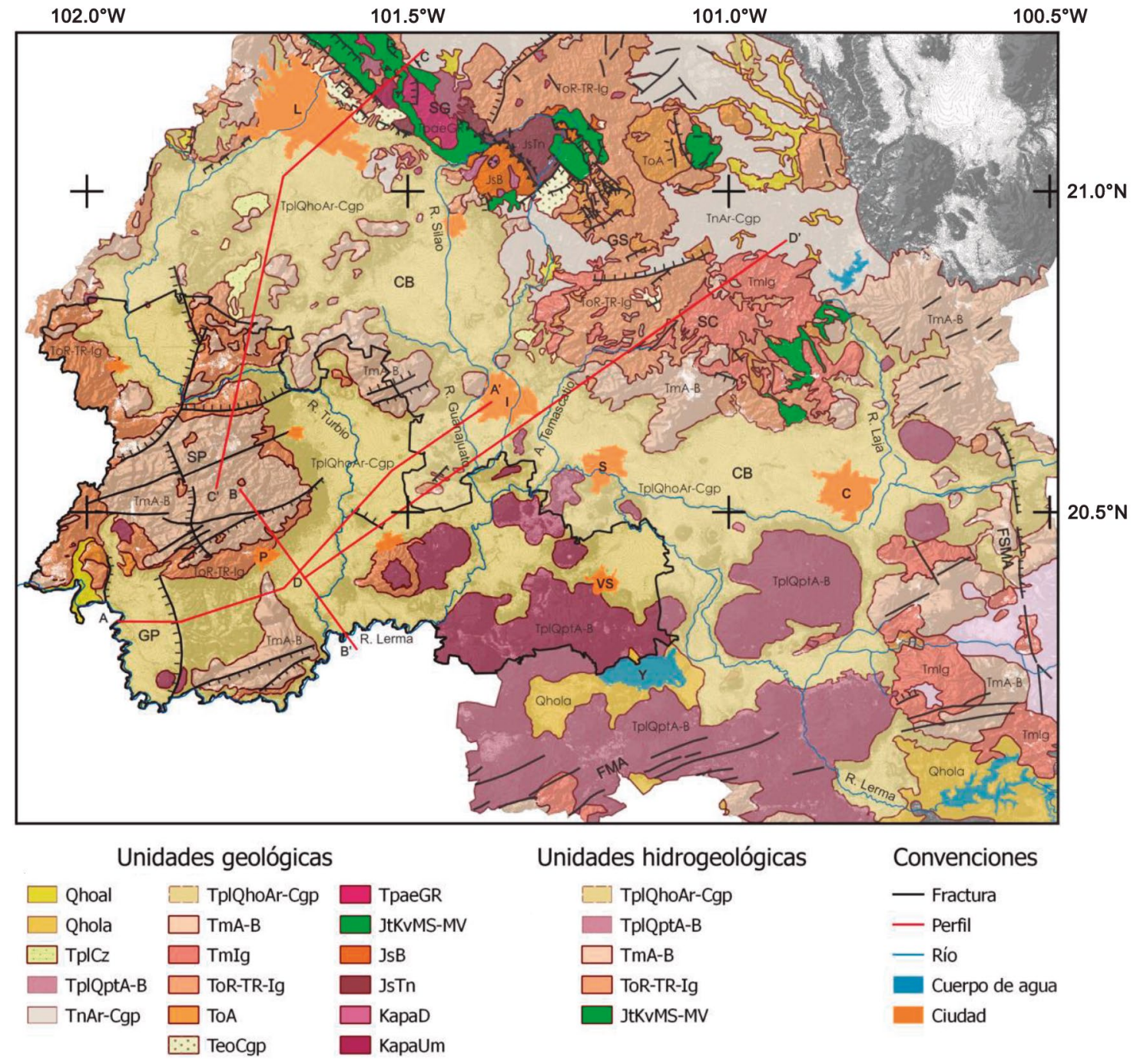

Figura 2. Mapa geológico de la zona de estudio. Tomado de la Carta Geológico-Minera de los estados de Guanajuato y Querétaro elaborada por el Servicio Geológico Mexicano en 1997. Los símbolos están referidos en las descripciones de las unidades estratigráficas. C: Celaya, I: Irapuato, L: León, P: Pénjamo, S: Salamanca, VS: Valle de Santiago, FB: Sistema de fallas del Bajío, FSMA: Falla San Miguel de Allende, FMA: Sistema de fallas Morelia-Acambay, CB: Cuenca del Bajío, GP: Graben Penjamillo, GS: Graben La Sauceda, SP: Sierra de Pénjamo, SG: Sierra de Guanajuato, SC: Sierra de Codornices.

determinó el grado de diferenciación de las aguas respecto a la corteza, y en el segundo, se identificaron patrones de ETR en agua y roca.

Las anomalías de $\mathrm{Ce}\left(\mathrm{Ce}^{*}\right)$ y Eu $\left(\mathrm{Eu}^{*}\right)$ en aguas subterráneas, para los valores normalizados a Lutita (en las fórmulas se usará la convención NS) fueron cuantificadas considerando la razón entre el valor obtenido de Ce y Eu con respecto a su valor esperado dada la tendencia de los ETR inmediatamente adyacentes, mediante las ecuaciones 1 y 2 respectivamente (Johannesson et al., 2005).

$$
\begin{gathered}
C e_{N S}^{*}=\log \frac{2 C e_{N S}}{L a_{N S}+P r_{N S}} \\
E u_{N S}^{*}=\log \frac{2 E u_{N S}}{S m_{N S}+G d_{N S}}
\end{gathered}
$$

Cabe mencionar que en petrología y geoquímica de rocas la notación $\mathrm{Eu}^{*}$ significa la relación que involucra mediciones del manto primitivo y los elementos de la vecindad inmediata a Eu.

El fraccionamiento de los Elementos de Tierras Raras Ligeros (ETRL) - del La al Eu - y los Elementos de Tierras Raras Pesados (ETRP)
- del Gd al Lu - (Henderson, 1984) fue calculado como $\mathrm{Yb}_{\mathrm{NS}} / \mathrm{Nd}_{\mathrm{NS}}$ (Johannesson et al., 2005). Las muestras de agua fueron clasificadas en diferentes familias de acuerdo al sentido (positivo o negativo) y magnitud de las anomalías de Ce y Eu (Middlesworth y Wood, 1998; Johannesson et al., 2005; Nelson et al., 2015, entre otros).

La especiación acuosa de ETR y los índices de saturación para determinadas fases minerales se realizó con la base de datos del "Lawrence Livermore National Laboratory" (LLNL) en el programa hidrogeoquímico PHREEQC (Parkhurst y Appelo, 2013). Las constantes termodinámicas de equilibrio de las especies $\mathrm{Ln}\left(\mathrm{CO}_{3}\right)_{2}{ }^{-}, \mathrm{LnCO}_{3}{ }^{+}$, $\mathrm{LnCl}^{+2}, \mathrm{LnCl}_{2}^{+}, \mathrm{LnCl}_{3}, \mathrm{LnCl}_{4}^{-}, \mathrm{LnHCO}_{3}^{+2}, \mathrm{LnOH}^{+2}$ y LnSO4 $4^{+}$fueron reemplazadas por los valores actualizados por Munemoto et al. (2015). Adicionalmente, las especies acuosas $\mathrm{Ln}(\mathrm{OH})_{2} \mathrm{CO}_{3}{ }^{-}, \mathrm{LnOH}\left(\mathrm{CO}_{3}\right)_{2}{ }^{-2}$ y $\mathrm{LnOHCO}_{3}$ fueron excluidas de la base de datos, ya que sus constantes de equilibrio sólo se presentaban para el Eu y la existencia de complejos de hidroxicarbonatos de Eu en solución no ha sido demostrada; por otro lado, los estudios de solubilidad de hidroxicarbonatos sólidos del resto de los ETR $\left(\mathrm{LnOHCO}_{3}\right)$ son escasos (Spahiu y Bruno, 1995). 


\section{RESULTADOS}

Elementos de Tierras Raras (ETR) en rocas

La Tabla 1a presenta las concentraciones promedio de ETR reportadas para nueve unidades estratigráficas de la FVTM (un total de 1342 muestras) y dos unidades de la SMOcc (con 68 muestras en total) por composición, evento y provincia geológica, donde (n) representa el número de muestras consideradas; de igual manera, en la Tabla 1b se presentan los valores normalizados a Condrita (Sun y McDonough, 1989) y en la Tabla 1c al Promedio Mundial de Lutita (Piper, 1974). En las Figuras 3a, 3b y 3c se muestra la gráfica de concentración de ETR reportada en rocas de la FVTM y su normalización a Condrita y a Lutita, respectivamente. Mientras que, para las rocas de la SMOcc, las concentraciones promedio y su respectiva

Tabla 1. a) Concentraciones promedio de ETR por composición, evento y provincia en ppm. b) Normalizadas a Condrita (Sun y McDonough, 1989). c) Normalizadas al Promedio Mundial de Lutita (Piper, 1974). FVTM1: Mioceno temprano a tardío; FVTM2: Pulso máfico del Mioceno tardío al Plioceno temprano; FVTM3: Vulcanismo silícico del Mioceno tardío a Plioceno temprano; FVTM4: Plioceno tardío a Cuaternario; SMOcc_Inf: Secuencia Inferior de la SMOcc; SMOcc Sup: Secuencia Superior de la SMOcc.

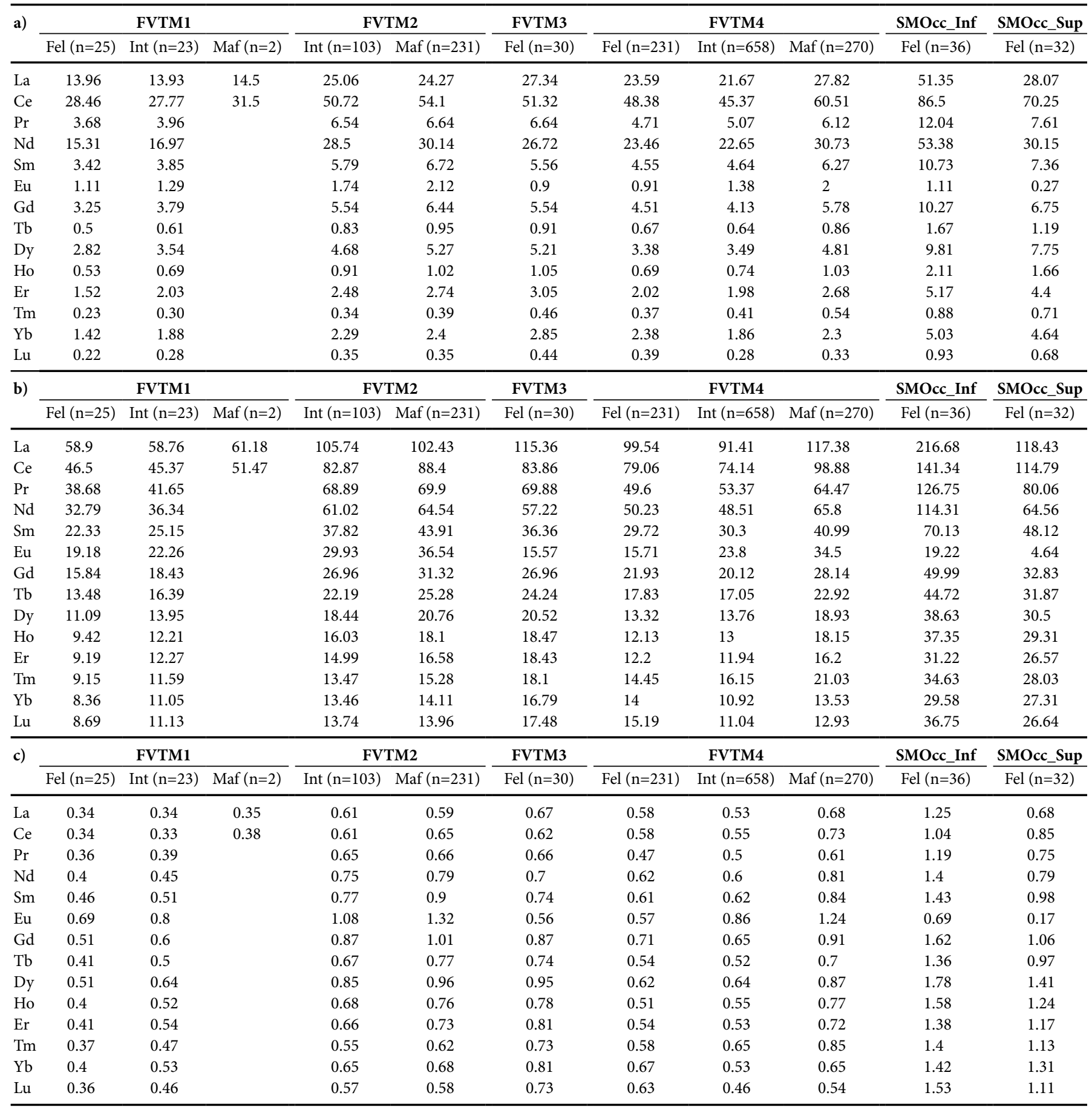



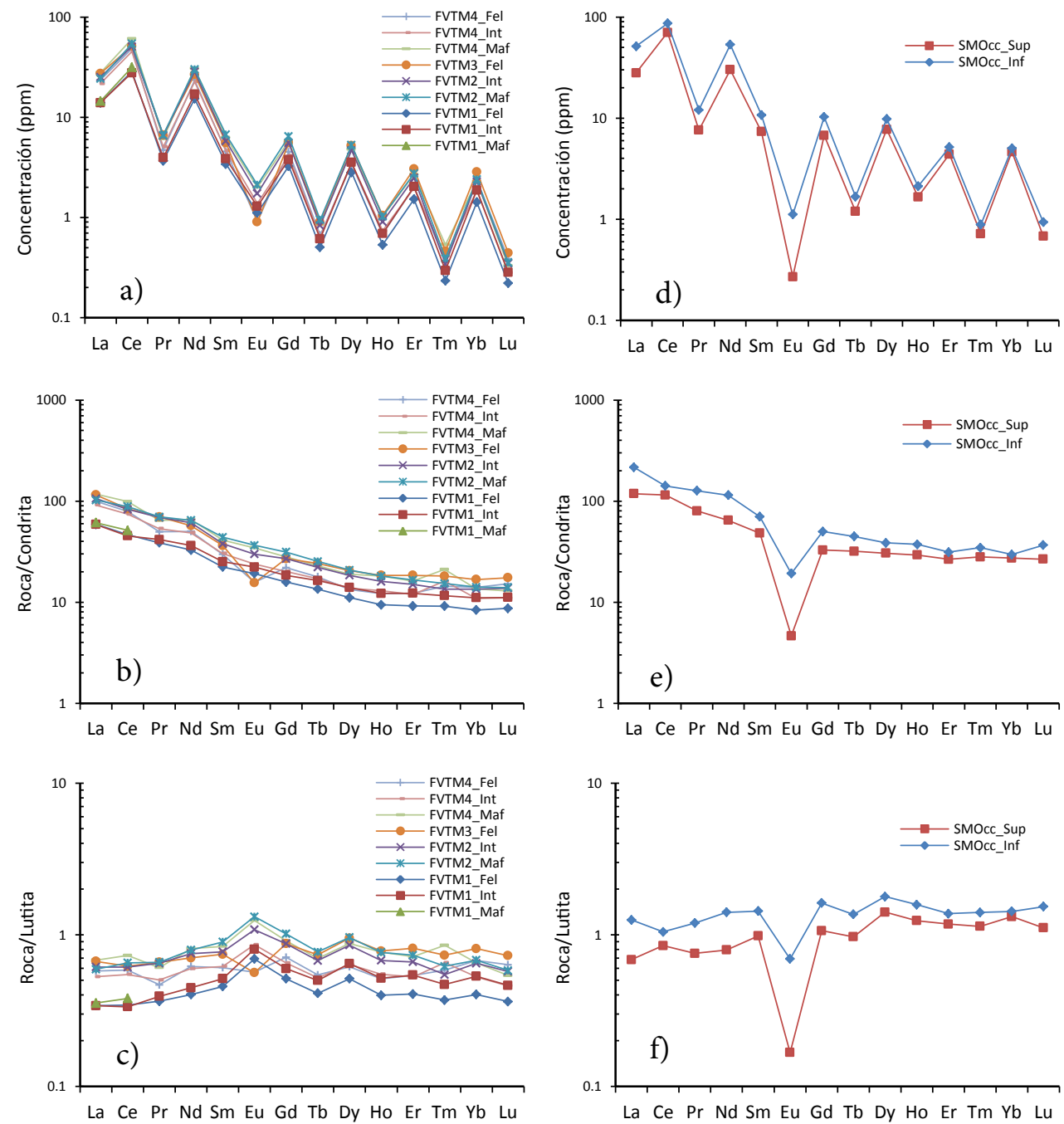

Figura 3. a) Diagrama de concentraciones promedio de ETR en rocas de la FVTM por composición y evento. b) Normalización al estándar Condrita (Sun y McDonough, 1989). c) Normalización al Promedio Mundial de Lutita (WSA, por sus siglas en inglés) (Piper, 1974). d) Diagrama de concentraciones promedio de ETR en rocas de la SMOcc por unidad. e) Normalización al estándar Condrita (Sun y McDonough, 1989).f) Normalización al Promedio Mundial de Lutita (Piper, 1974).

normalización a Condrita y a Lutita se muestran en las Figuras 3d, 3e y 3f, respectivamente.

En general, el promedio de la concentración de ETR es mayor en las rocas de la SMOcc (Figura 3d) que en las de la FVTM (Figura 3a); mientras que, los patrones de ETR de las rocas normalizados a Condrita (NC) (Figuras 3b y 3e) difieren de los normalizados a Lutita (Figuras 3c y 3f). La normalización con respecto a Condrita muestra sólo una anomalía de Eu para las rocas del vulcanismo silícico del Mioceno tardío al Plioceno temprano (FVTM3-Fel) (Figura 3b); en cambio, para las rocas de la SMOcc, ambos grupos presentan una marcada anomalía de Eu (Figura 3e). En cuanto a los patrones que define la normalización a Lutita, se mantiene la anomalía negativa de Eu en las rocas de la SMOcc (Figura 3f), que contrastan con una anomalía positiva de Eu en todas las rocas de la FVTM, excepto los promedios de composición félsica de FVTM3 y FVMT4.

\section{ETR en rocas de la Sierra de Pénjamo}

La concentración de ETR en rocas de la Sierra de Pénjamo se muestran en la Tabla 2 y en la gráfica de la Figura 4a, donde las concentraciones de Ce son de 107.97 (ToIg-01C) y 97.62 ppm (ToIg-02P); mientras que la concentración de ETR normalizados con respecto a Condrita presenta una anomalía de Eu (Figura 4b), con valores de - 0.67 (ToIg-02P) y -0.87 (ToIg-01C).

Los patrones de ETR normalizados a Condrita de la roca ToIg-01C con los promedios de la secuencia superior y de la roca ToIg-02P con la secuencia inferior de la SMOcc (Figuras $3 \mathrm{f}$ y $4 \mathrm{~b}$ ) muestra ciertas semejanzas, como la marcada anomalía de Eu; sin embargo, la muestra ToIg-01C, presenta una anomalía positiva de Ce, que sólo se manifiesta ligeramente en el miembro inferior de la SMOcc.

\section{Elementos de Tierras Raras (ETR) en agua subterránea}

Concentración de ETR en solución

La ubicación de las muestras se muestra en la Figura 5, donde se incluye la litología regional. En la Figura 6 se presenta el diagrama de caja, el cual muestra el rango de concentración de $\Sigma$ ETR disueltos en agua subterránea, la mediana, la dispersión y la simetría de las 94 muestras analizadas. El Ce se encuentra en un amplio rango de concentración, desde unos cuantos nanogramos por litro hasta concentraciones cercanas a $0.5 \mathrm{mg} / \mathrm{L}$. El $46 \%$ de los ETR como el terbio $(\mathrm{Tb})$, 
Tabla 2. Concentraciones medidas, normalizadas a Condrita (NC) y normalizadas al Promedio Mundial de Lutita (NS) de las ignimbritas de la SMOcc muestreadas en la Sierra de Pénjamo.

\begin{tabular}{lccccccc}
\hline & \multicolumn{3}{c}{ ToIg-01C } & & \multicolumn{3}{c}{ Tolg-02P } \\
\cline { 2 - 3 } \cline { 6 - 7 } & $\begin{array}{c}\text { Concentración } \\
(\mathrm{ppm})\end{array}$ & $\begin{array}{c}\text { Concentración } \\
\text { NC }\end{array}$ & $\begin{array}{c}\text { Concentración } \\
\text { NS }\end{array}$ & $\begin{array}{c}\text { Concentración } \\
(\mathrm{ppm})\end{array}$ & $\begin{array}{c}\text { Concentración } \\
\text { NC }\end{array}$ & $\begin{array}{c}\text { Concentración } \\
\text { NS }\end{array}$ \\
\hline $\mathbf{L a}$ & 20.95 & 88.41 & 0.51 & & 54.33 & 229.25 & 1.33 \\
$\mathbf{C e}$ & 107.97 & 176.43 & 1.30 & & 97.62 & 159.51 & 1.18 \\
$\mathbf{P r}$ & 6.33 & 66.63 & 0.63 & & 14.49 & 152.52 & 1.43 \\
$\mathbf{N d}$ & 26.28 & 56.28 & 0.69 & & 56.38 & 120.73 & 1.48 \\
$\mathbf{S m}$ & 6.65 & 43.49 & 0.89 & & 13.14 & 85.86 & 1.75 \\
$\mathbf{E u}$ & 0.31 & 5.31 & 0.19 & & 0.89 & 15.36 & 0.55 \\
$\mathbf{G d}$ & 7.42 & 36.08 & 1.17 & & 11.77 & 57.29 & 1.85 \\
Tb & 1.29 & 34.58 & 1.05 & & 1.99 & 53.11 & 1.61 \\
$\mathbf{D y}$ & 7.92 & 31.16 & 1.44 & & 11.60 & 45.67 & 2.11 \\
$\mathbf{H o}$ & 1.57 & 27.71 & 1.17 & & 2.20 & 38.80 & 1.64 \\
$\mathbf{E r}$ & 4.55 & 27.48 & 1.21 & & 6.41 & 38.71 & 1.71 \\
$\mathbf{Y b}$ & 3.98 & 23.40 & 1.13 & & 6.04 & 35.51 & 1.71 \\
$\mathbf{L u}$ & 0.57 & 22.35 & 0.93 & 0.88 & 34.83 & 1.45 \\
\hline
\end{tabular}

holmio (Ho), tulio $(\mathrm{Tm})$ y lutecio $(\mathrm{Lu})$ se encuentran por debajo del límite de detección. Sin embargo, esto no representa una limitación a la interpretación en el comportamiento de otros elementos, cuyas concentraciones y anomalías pueden ser representativas de la interacción agua-roca y de las reacciones asociadas.

\section{Normalización de ETR y familias de agua}

Los resultados de ETR disueltos en agua subterránea fueron normalizados con respecto al Promedio Mundial de Lutita, y posteriormente clasificadas en familias (Tabla 3) considerando: 1) Las anomalías de cerio $\left(\mathrm{Ce}^{*}{ }_{\mathrm{NS}}\right)$ y europio $\left(\mathrm{Eu}^{*}{ }_{\mathrm{NS}}\right)$ calculadas con las ecuaciones 1 y 2 ; y que estas dos anomalías son ampliamente usadas en la literatura por ser los más sensibles en el campo de estabilidad en los diagramas Eh-pH del agua (Brookins, 1983; Noack et al., 2014); 2) La relación $\mathrm{Yb}_{\mathrm{NS}} / \mathrm{Nd}_{\mathrm{NS}}$, que indica el grado de fraccionamiento de ETRP y ETRL, donde los valores mayores a 1 implican el enriquecimiento relativo de los ETRP y los menores a 1, el de los ETRL (Tabla 3).

A partir de estos dos criterios, 81 muestras son consideradas en los grupos $\mathrm{A}, \mathrm{B}$ y C donde la relación $\mathrm{Yb}_{\mathrm{NS}} / \mathrm{Nd}_{\mathrm{NS}}$ muestra, en general, enriquecimiento de los ETRP sobre los ETRL (Figuras 7a-7c). El rango de variación en las concentraciones, la media y el límite de detección de estas tres familias se muestra en las Figuras $7 a^{\prime}-7 c^{\prime}$. Las trece muestras restantes se clasificaron en los grupos D a I (Figuras 8a-8f). El grupo A presenta una anomalía negativa de Ce muy pronunciada $\left(\mathrm{Ce}^{*}{ }_{\mathrm{NS}}<-0.25\right)$, las concentraciones de Eu son relativamente bajas por lo que no es posible determinar la magnitud de la anomalía, y el rango de ETRL es más acotado que en $\mathrm{B}$ y $\mathrm{C}$. El grupo $\mathrm{C}$ presenta anomalías de $\mathrm{Ce}$ muy pequeñas $\left(-0.25<\mathrm{Ce}^{*}{ }_{\mathrm{NS}}<0.25\right)$ y anomalías de Eu fuertemente positivas $\left(\mathrm{Eu}^{*}{ }_{\mathrm{NS}}>0.25\right)$. Por otra parte, el grupo B representa condiciones intermedias entre $\mathrm{A}$ y $\mathrm{C}$ con anomalías muy pequeñas tanto de Ce como de Eu y un amplio rango de concentraciones de ETRL, a excepción del Eu.

Otra característica importante de los grupos de muestras A, B y C, es su distribución espacial en el área de estudio (Figuras 1 b y 5). El grupo A se ubica preferencialmente en la falda de las sierras de los límites norte y oriental de la zona de estudio, próximas a los cauces de los ríos Turbio, Guanajuato y Lerma; el grupo B se encuentra principalmente en la periferia y sobre las sierras de la porción austral, ambos en el área de influencia del acuífero fracturado; y el grupo C está en las partes bajas, en las llanuras de los ríos Turbio y Lerma, en el acuífero granular.

Los grupos D a I (Figura 8a-8f) indican poco fraccionamiento entre los ETRL y los ETRP debido a diferencias en el sentido y la magnitud de las anomalías de Ce y Eu, y la combinación de éstas, sumado a que los valores de $\mathrm{Yb}_{\mathrm{NS}} / \mathrm{Nd}_{\mathrm{NS}}$ son muy pequeños y cercanos a 1 (de 0.191 a 3.132 excluyendo el grupo I).

Los grupos D, E, F y G (Figuras 8a-8d) presentan las concentraciones de ETR totales más altas medidas en todas las muestras de
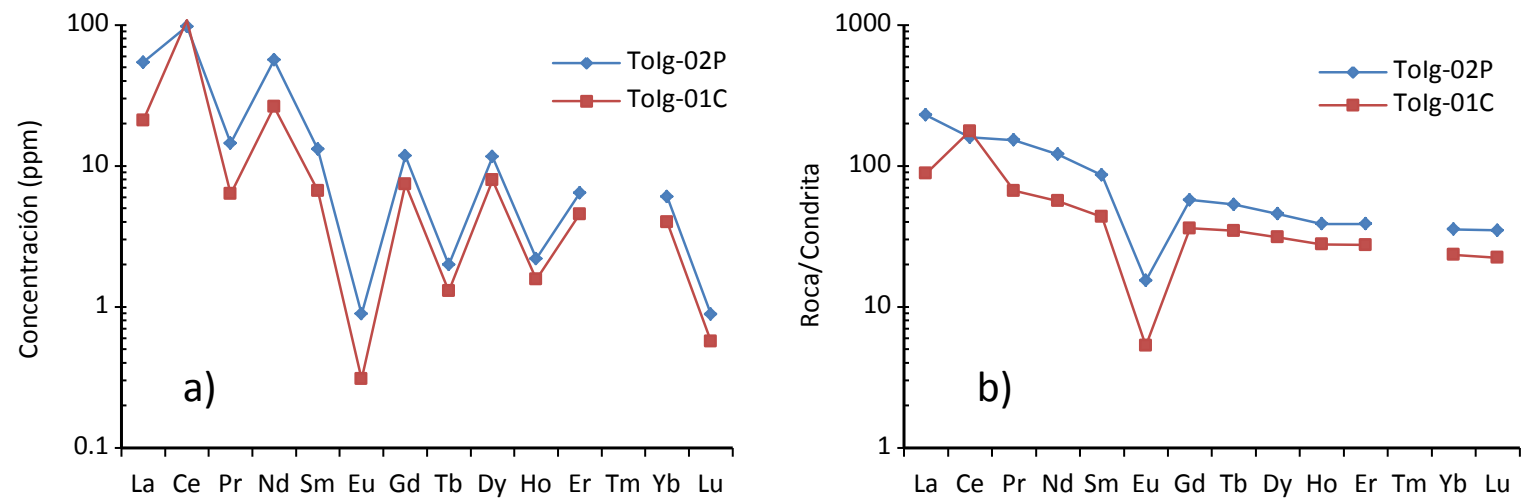

Figura 4. a) Concentraciones de ETR en ignimbritas de la Sierra de Pénjamo. b) Normalización respecto al estándar Condrita. 


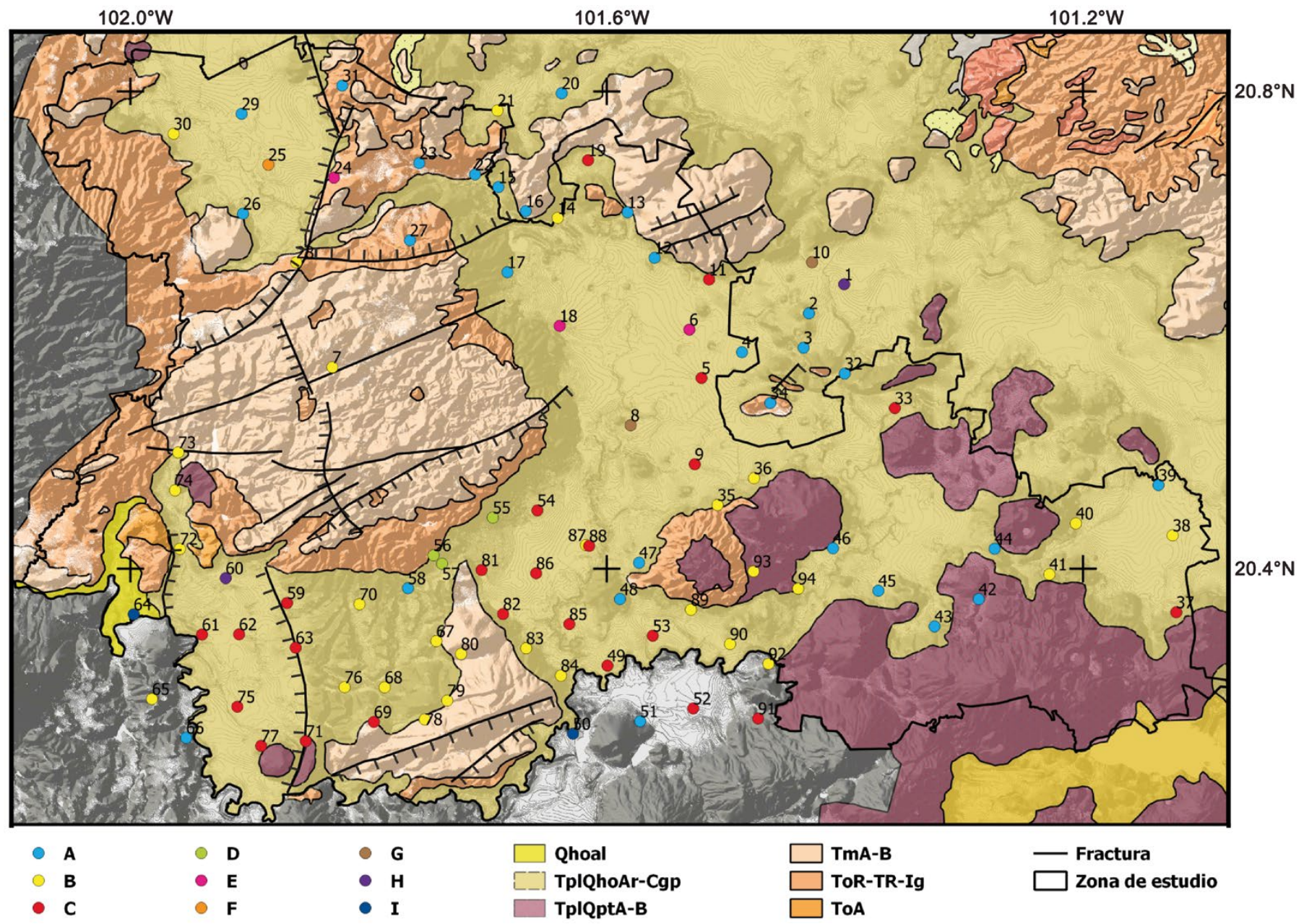

Figura 5. Mapa de localización de las muestras de agua y las diferentes unidades hidrogeológicas descritas. Familias de aguas subterráneas en función de la concentración de ETR. Como fondo, se observa el relieve en tonos oscuros; las zonas topográficamente bajas tienen tonos claros.

agua ( $\sum E T R$ de 117 a $1815 \mathrm{mg} / \mathrm{L}$ ). El grupo D presenta una anomalía negativa de Ce bastante incipiente y una anomalía negativa de Eu de magnitud considerable. La principal diferencia entre el grupo D y el grupo E, es que, en el segundo, la anomalía negativa de Eu es mucho más prominente. La muestra del grupo $\mathrm{F}$ es única entre las demás por la anomalía positiva de Ce tan sobresaliente, al igual que su deducible anomalía negativa de Eu. Aunque las muestras de agua del grupo G tienen características similares a los del grupo B, es decir anomalías pequeñas de $\mathrm{Ce}$ y Eu, las altas concentraciones de ETR y su posición espacial permiten evaluarlo como un conjunto diferente.

A pesar de la escasez de datos en el grupo H (Figura 8e), las anomalías positivas de Ce y Eu son de gran magnitud respecto a sus vecinos más próximos, los cuales llegan a estar incluso por debajo del límite de detección. El grupo I (Figura 8f) exhibe una anomalía negativa de Ce moderada y una marcada anomalía positiva de Eu, además de un fuerte enriquecimiento de ETRP respecto a los ETRL; por estas características y su influencia litológica, las muestras de este grupo, 64 y 50, eventualmente pueden llegar a ser incluidas en el grupo C (Figura 7c).

\section{Potencial de Hidrógeno $(p H)$}

La concentración de ETR en función del $\mathrm{pH}$ para la zona de estudio se observa en la Figura 9a, donde el rango de variación del pH es entre

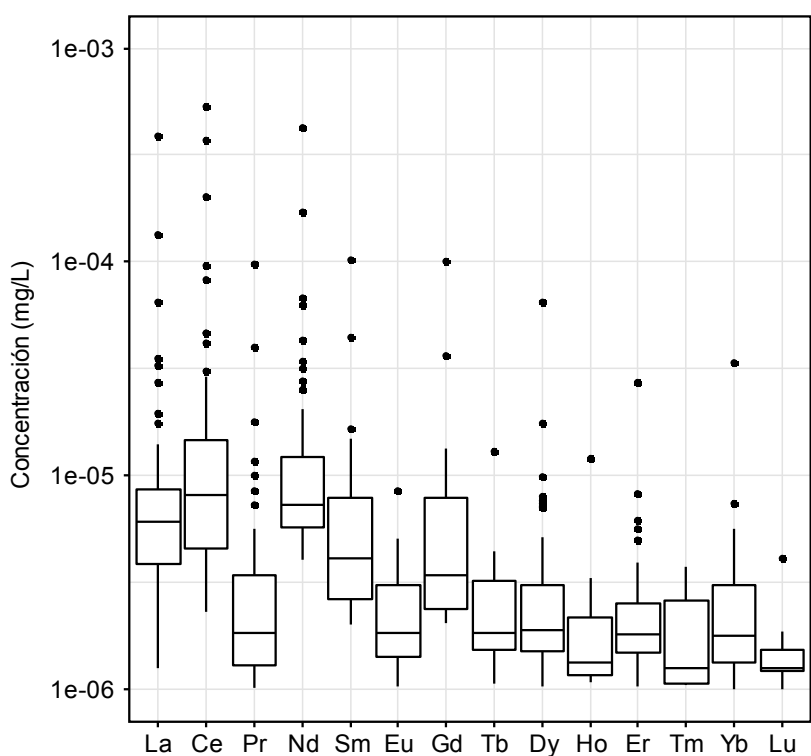

Figura 6. Diagramas de caja de las concentraciones de cada ETR en las 94 muestras de agua subterránea. 
Tabla 3. Clasificación de las muestras de agua considerando la anomalía de Ce y la anomalía de Eu. NS: Valores normalizados al Promedio Mundial de Lutita

\begin{tabular}{llccc}
\hline Familia & & $\mathrm{Yb}_{\mathrm{NS}} / \mathbf{N}_{\mathrm{dNS}}$ & $\mathrm{Ce}^{*}{ }_{\mathrm{NS}}$ & $\mathrm{Eu}^{*}{ }_{\mathrm{NS}}$ \\
\hline $\mathrm{A}(\mathrm{n}=28)$ & Mín. & 1.689 & -0.528 & --- \\
& Máx. & 8.564 & -0.283 & --- \\
$\mathrm{B}(\mathrm{n}=29)$ & Mín. & 0.910 & -0.184 & -0.028 \\
& Máx. & 5.993 & 0.072 & 0.235 \\
$\mathrm{C}(\mathrm{n}=24)$ & Mín. & 1.136 & -0.150 & 0.273 \\
& Máx. & 6.158 & 0.224 & 0.832 \\
$\mathrm{D}(\mathrm{n}=3)$ & Mín. & 0.563 & -0.227 & -0.447 \\
& Máx. & 0.859 & -0.131 & -0.442 \\
$\mathrm{E}(\mathrm{n}=3)$ & Mín. & 0.191 & -0.063 & -0.955 \\
& Máx. & 3.132 & 0.093 & -0.955 \\
$\mathrm{~F}(\mathrm{n}=1)$ & Mín. & 1.040 & 0.750 & --- \\
& Máx. & 1.040 & 0.750 & --- \\
$\mathrm{G}(\mathrm{n}=2)$ & Mín. & 0.212 & -0.177 & 0.090 \\
& Máx. & 0.808 & -0.111 & 0.187 \\
$\mathrm{H}(\mathrm{n}=2)$ & Mín. & --- & --- & --- \\
& Máx. & --- & --- & --- \\
$\mathrm{I}(\mathrm{n}=2)$ & Mín. & 4.762 & -0.303 & 0.392 \\
& Máx. & 4.762 & -0.303 & 0.392 \\
\hline
\end{tabular}

5.9 y 8.08 , con un promedio de 7.29 y una varianza de 0.12 . Este rango es consistente con los resultados obtenidos en el mundo (Figura 9b) (Noak et al., 2014).

\section{Especiación acuosa de ETR}

Se escogieron tres muestras de agua subterránea $(55,85$ y 86$)$ ubicadas a lo largo de una sección orientada NW-SE (Figura 5) para modelar la especiación de ETR. La muestra 55 se encuentra en el piedemonte sur de la Sierra de Pénjamo, considerada una zona de recarga local, y las muestras 85 y 86 se ubican en el valle del Río Turbio. Según el mapa de nivel estático de la CEAG (2001), en las últimas décadas se ha generado una depresión piezométrica en esta zona, causando que las aguas provenientes de la Sierra de Pénjamo, al noroeste (muestra 55) y las que circulan al sureste del Río Turbio (muestra 85) converjan en las proximidades del pozo 86.

Los resultados obtenidos para cada una de las muestras se presentan en la Figura 10a-10c, donde se grafica el porcentaje molar de cada uno de los ETR, mientras que en la Figura 10d se muestra la especiación en función del pH. Dado el dominio de la familia de agua bicarbonatada sódica en la zona de estudio (Ortega-Guerrero 2000; CEAG, 2001), los complejos acuosos de ETR dominantes son los carbonatos, específicamente $\mathrm{LnCO}_{3}{ }^{+}$y $\mathrm{Ln}\left(\mathrm{CO}_{3}\right)_{2}$, donde $\mathrm{Ln}$ es el ETR en cuestión. Es
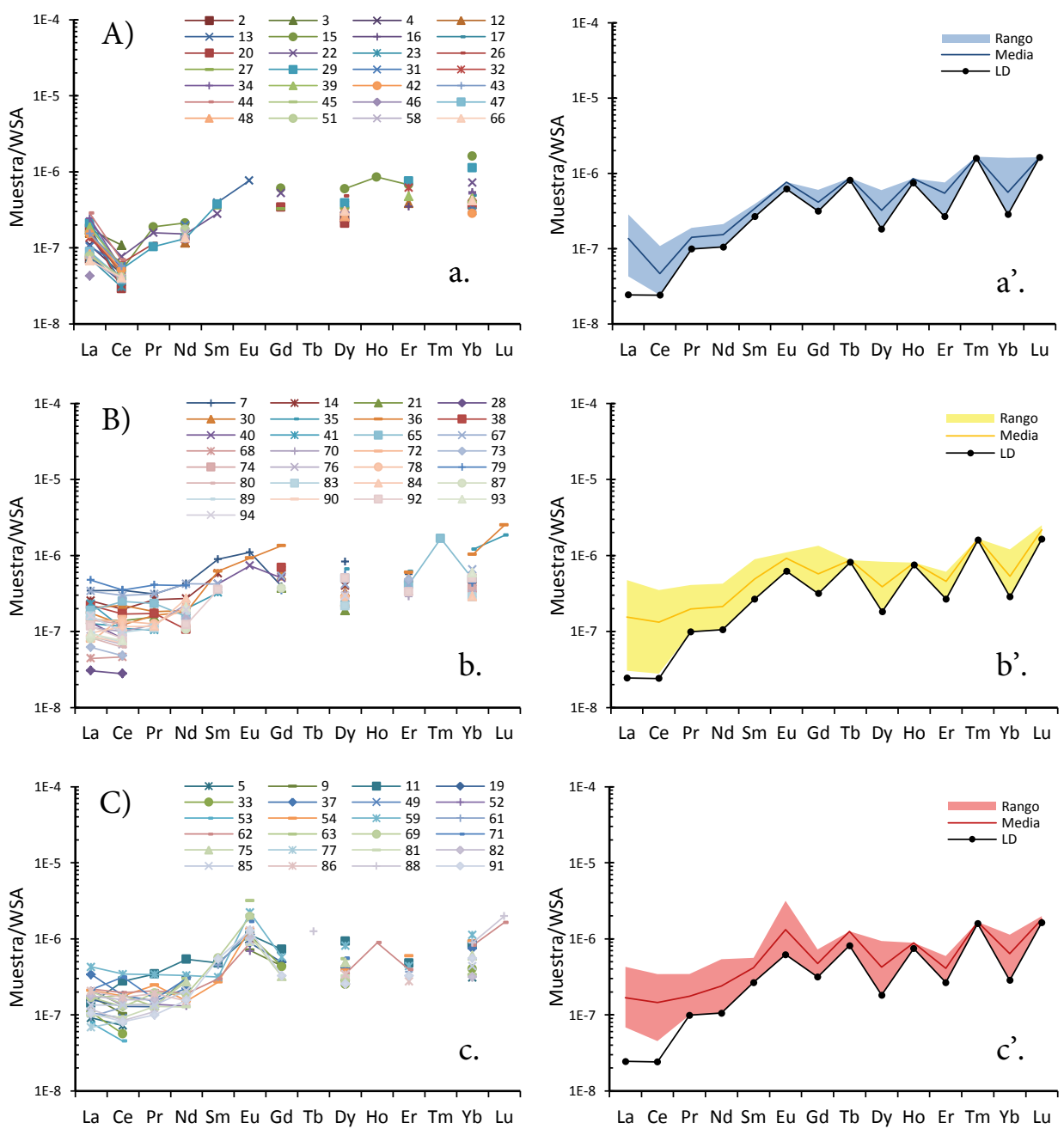

Figura 7. Patrones de ETR de las familias A, B y C, y rangos y medias de muestras normalizadas al Promedio Mundial de Lutita (WSA). LD: Límite de detección. 


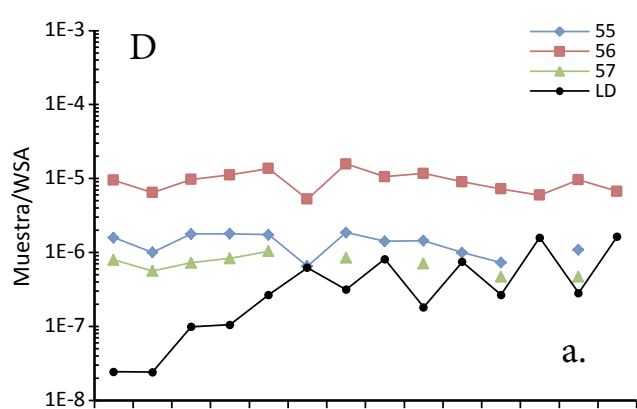

La Ce Pr Nd Sm Eu Gd Tb Dy Ho Er Tm Yb Lu
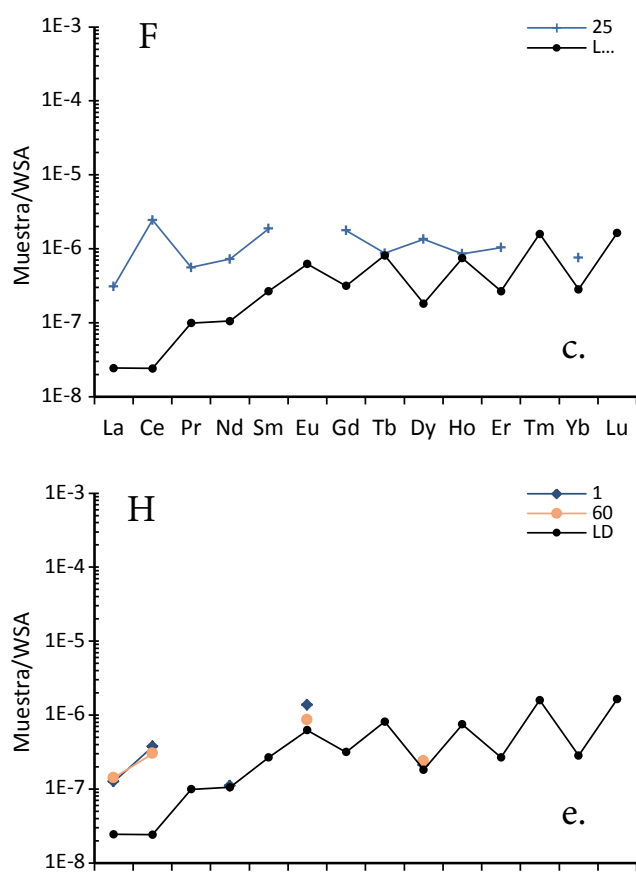

La Ce Pr Nd Sm Eu Gd Tb Dy Ho Er Tm Yb Lu
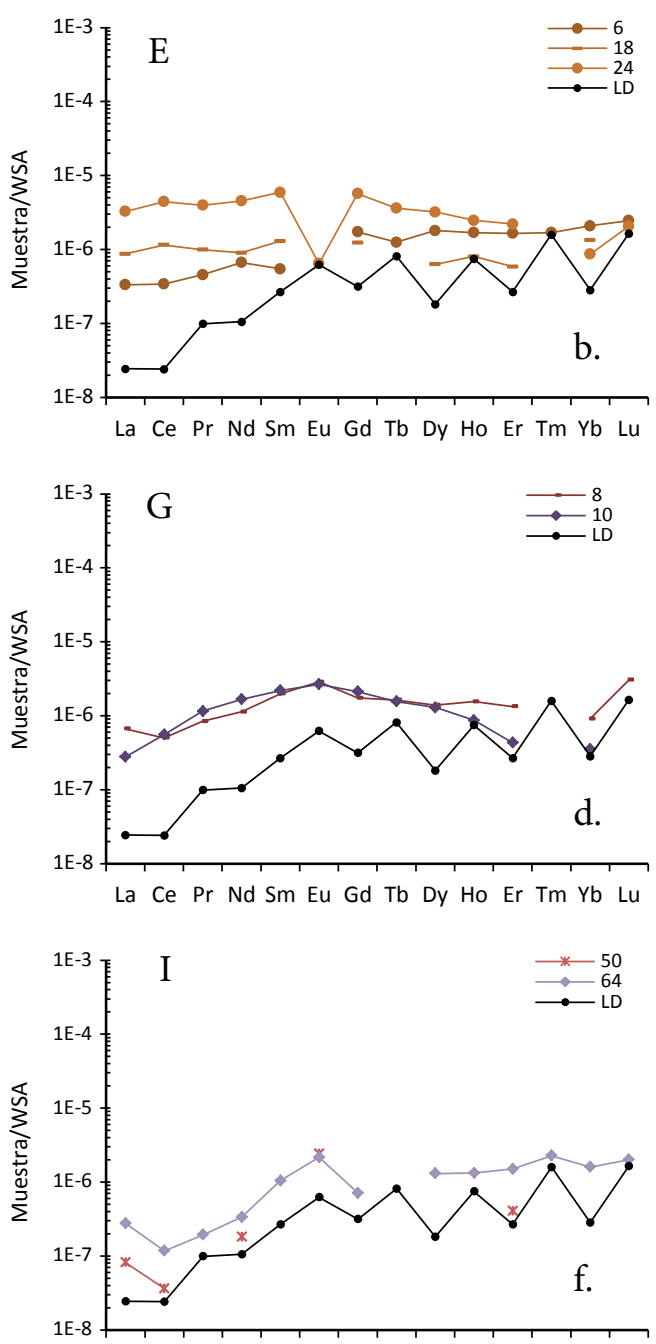

La Ce Pr Nd Sm Eu Gd Tb Dy Ho Er Tm Yb Lu

Figura 8. Patrones de ETR de las familias D-I normalizadas al Promedio Mundial de Lutita (WSA). LD: Límite de detección.
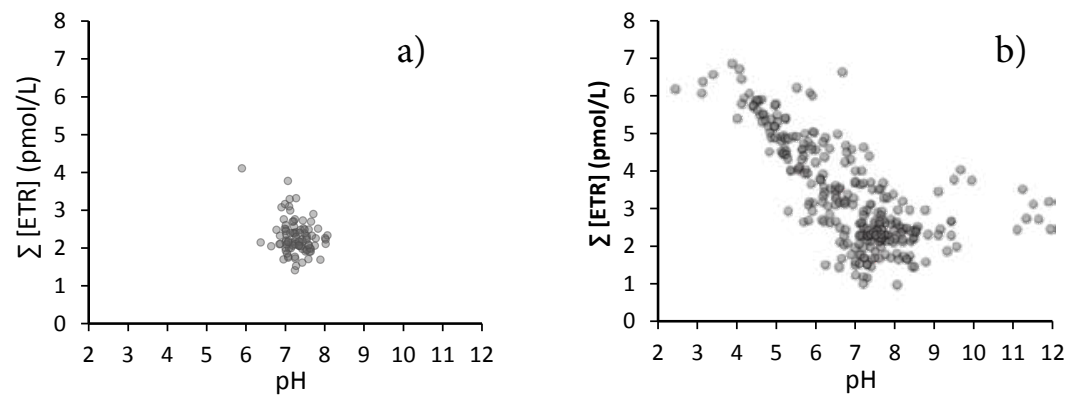

Figura 9. Concentración de ETR disueltos vs. pH: a) En agua subterránea del área de estudio y b) En 281 muestras de aguas subterráneas de diferentes estudios a nivel global (tomada de Noack et al., 2014). La densidad de los datos se representa por el grado de transparencia. 
oportuno indicar que el predominio de los complejos carbonatados en aguas subterráneas de $\mathrm{pH}$ cercano a neutral ha sido documentado en diferentes lugares del mundo por diferentes autores (Johannesson et al., 1997; Yuan et al., 2014; Nelson et al., 2015; Sikakwe et al., 2016).

Los diagramas de especiación de las muestras 55 y 86 son bastante similares (Figuras 10a-c). El ligando dominante para todas las ETR es el $\mathrm{LnCO}_{3}{ }^{+}$, el cual capta entre el 81 y el $93 \%$ del total de las moles disueltas de cada uno de los ETR; este porcentaje tiende a disminuir ligeramente hacia los ETRP. El siguiente ligando en importancia por su abundancia es el $\mathrm{Ln}\left(\mathrm{CO}_{3}\right)_{2}$ - incorporando hasta un $12 \%$ del total de moles disueltas del ETR; a diferencia de las especies de carbonato, el porcentaje de especies de bicarbonato tiende a aumentar progresivamente hacia los ETRP. Los ETR como iones libres $\left(\mathrm{Ln}^{+3}\right)$ ocupan el tercer lugar en abundancia, con porcentajes entre 0.7 y 10 , siendo significativamente mayor en los ETRL y con una disminución paulatina hacia los ETRP. Los sulfatos $\left(\mathrm{LnSO}_{4}^{-}\right)$pueden llegar a ser especies importantes, sobre todo en los ETR más ligeros donde pueden significar hasta el $6 \%$ de los complejos formados.

Los resultados de la especiación de la muestra 85 contrastan fuertemente con los de las muestras ya descritas. El aspecto más sobresaliente es el intercambio en abundancia de las especies $\mathrm{LnCO}_{3}{ }^{+}$y $\mathrm{Ln}\left(\mathrm{CO}_{3}\right)_{2}$ entre los ETRL y los ETRP. La abundancia en moles de $\mathrm{LnCO}_{3}{ }^{+}$varía de $84 \%$ en el La, el ETR más ligero, a cerca de $48 \%$ en el Yb, uno de los ETR más pesados. Por el contrario, el porcentaje molar de las especies de $\mathrm{Ln}\left(\mathrm{CO}_{3}\right)_{2}{ }^{-}$varía de 14 en el $\mathrm{La}$ a 52 en el Yb. Por otra parte, los iones libres y los complejos sulfatados, siguientes en abundancia, suman menos del $2 \%$ de las moles del ETR, siendo mayor en los ETRL.

\section{Índices de saturación}

Los Índices de Saturación (SI, por sus siglas en inglés) de los principales minerales que pueden formar ETR, calculados por el programa PHREEQC, se muestran en la Tabla 4 y de otros minerales de interés en la Tabla 5. Los compuestos de ETR están, en general, sub-saturados en el agua subterránea y por tanto ésta puede incorporarlos a través de su disolución (Tabla 5). La calcita y el yeso, que pueden incorporar ETR en su estructura cristalina por su similitud en el radio iónico con el $\mathrm{Ca}^{+2}$ (Noack et al., 2014), también presentan condiciones de subsaturación; en contraste, el feldespato alcalino, la albita, arcillas como la caolinita y la illita, y la calcedonia, que también pueden incorporar ETR en su estructura, presentan índices de saturación positivos (Tabla 5). La sobresaturación de feldespatos y arcillas indica una intensificada disolución de feldespatos, generando una alta tasa de formación de arcillas.

\section{Simulación de mezclas de agua}

Cuando el agua subterránea ha interactuado con más de un tipo de roca es de esperarse que la firma geoquímica que presenta sea producto de las nuevas condiciones de equilibrio que se establecen a partir de la composición química adquirida y de las nuevas condiciones litológicas que encontrará en su recorrido (Palmer y Cherry, 1984). Como se vio anteriormente, la firma geoquímica de ETR de las rocas de la SMOcc y la FVTM no son suficientes para explicar el origen de los patrones de ETR de las diferentes familias de agua, ya que más allá de la anomalía de Eu y la concentración absoluta de ETR, estas firmas no difieren significativamente; por otro lado, las anomalías de Ce de gran magnitud de las familias A, F, H, I y las anomalías fuertemente positivas de Eu en las familias C, H e I, no se pueden obtener a partir de la interacción exclusiva con las riolitas e ignimbritas de la SMOcc y/o los basaltos y andesitas de la FVTM.

Aunque no se cuenta con la firma geoquímica de las rocas marinas de la base de la secuencia estratigráfica ni con la de los sedimentos de relleno del acuífero granular de la zona, se utilizó el programa a)

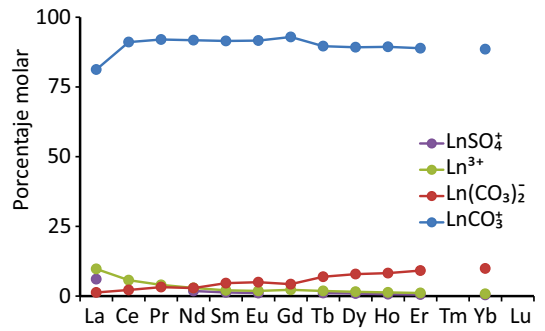

b)

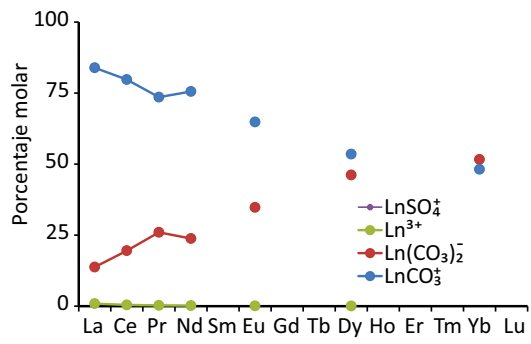

c)
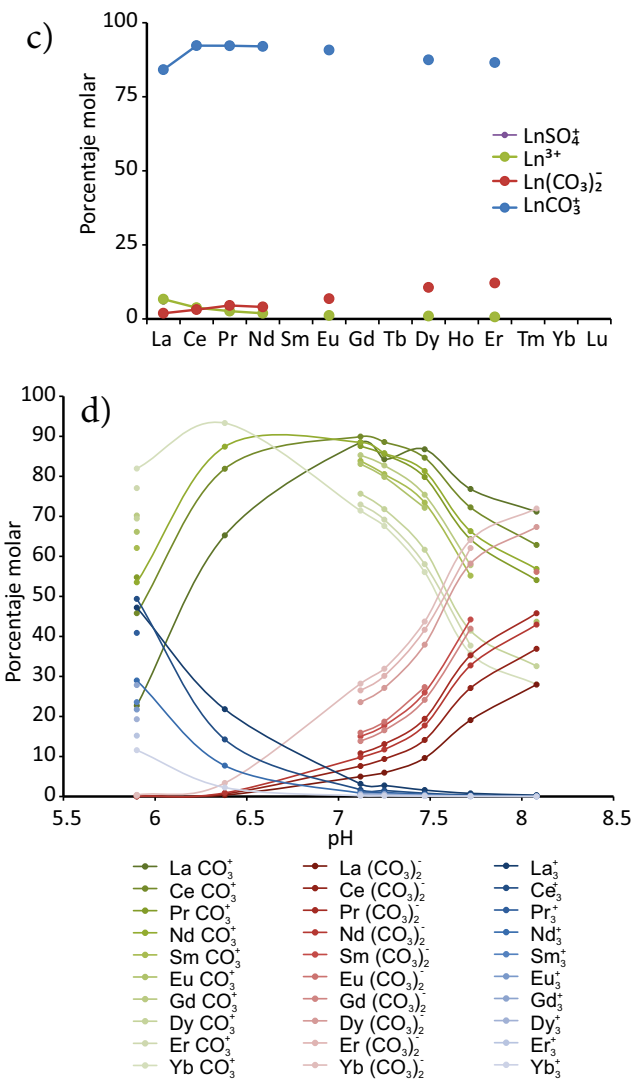

Figura 10. Porcentaje en moles de complejos para cada ETR resultado de la especiación en las muestras: a) 55; b) 85 y c) 86 .

geoquímico PHREEQC para simular la composición de ETR bajo diferentes mezclas de agua característica de rocas marinas, identificada como C100, y agua proveniente del acuífero granular, cuya firma puede ser atribuida en mayor medida a las plagioclasas de los basaltos de la FVTM, identificada como P100. En la Figura 11a se muestran los resultados de estas simulaciones. En la Figura 11b se presentan muestras de la Familia A normalizadas al Promedio Mundial de Lutita (WSA) y a la mezcla de agua de rocas marinas (P10C90) en $90 \%$ y del acuífero granular en $10 \%$; en la Figura 11c se encuentran muestras de 
Tabla 4. Índices de saturación de los principales minerales que pueden formar los ETR, de acuerdo a la composición del agua en las respectivas muestras. ${ }^{*}$ El mineral se presenta en su variedad octahidratada $\left(\operatorname{Ln}_{2}\left(\mathrm{CO}_{3}\right)_{3}: 8 \mathrm{H}_{2} 0\right),{ }^{* *} \mathrm{El}$ mineral se presenta en su variedad trihidratada $\left(\operatorname{Ln}_{2}\left(\mathrm{CO}_{3}\right)_{3}: 8 \mathrm{H}_{2} 0\right)$.

\begin{tabular}{|c|c|c|c|c|c|c|}
\hline Muestra & ETR & Ln & $\operatorname{Ln}(\mathrm{OH})_{3}$ & $\operatorname{Ln}(\mathrm{OH})_{3}(\mathrm{am})$ & $\operatorname{Ln}_{2} \mathrm{O}_{3}$ & $\mathrm{Ln}_{2}\left(\mathrm{CO}_{3}\right)_{3}$ \\
\hline \multirow[t]{12}{*}{55} & $\mathrm{La}$ & -138.18 & -9.57 & -12.77 & -44.77 & $*-3.86$ \\
\hline & $\mathrm{Ce}$ & -136.61 & -9.33 & -10.63 & -41.19 & * -4.39 \\
\hline & $\operatorname{Pr}$ & -138.12 & -9.83 & -11.33 & -41.19 & -6.29 \\
\hline & $\mathrm{Nd}$ & -136.25 & -7.9 & -10.3 & -38.23 & -5.57 \\
\hline & $\mathrm{Sm}$ & & -7.18 & -9.28 & -24.3 & -7.49 \\
\hline & $\mathrm{Eu}$ & -122.4 & -7.92 & & -36.6 & $* *-9.12$ \\
\hline & Gd & -135.79 & -6.37 & -8.77 & -35.37 & -7.46 \\
\hline & $\mathrm{Tb}$ & -137.31 & -7.37 & -10.47 & -30.47 & -9.77 \\
\hline & Dy & -136.15 & -7 & -8.6 & -29.22 & -8.82 \\
\hline & Ho & -138.97 & -7.35 & -9.75 & -31.23 & -10.73 \\
\hline & Er & -137.64 & -6.72 & -10.72 & -25.57 & -10.47 \\
\hline & $\mathrm{Yb}$ & & -6.44 & -10.74 & -31.31 & -10.8 \\
\hline \multirow[t]{7}{*}{85} & $\mathrm{La}$ & -143.37 & -8.86 & -12.06 & -43.35 & * -5.16 \\
\hline & $\mathrm{Ce}$ & -141.77 & -71 & -102 & -39.79 & * -5.7 \\
\hline & $\operatorname{Pr}$ & -143.52 & -9.34 & -10.84 & -40.92 & -8.03 \\
\hline & $\mathrm{Nd}$ & -141.39 & -7.19 & -9.59 & -36.81 & -6.87 \\
\hline & $\mathrm{Eu}$ & -126.84 & -7.37 & & -36.09 & $* *-10.28$ \\
\hline & Dy & -141.13 & -6.12 & -7.72 & -27.48 & -9.79 \\
\hline & $\mathrm{Yb}$ & & -5.4 & -9.7 & -29.24 & -11.45 \\
\hline \multirow[t]{7}{*}{86} & $\mathrm{La}$ & -141.32 & -10.57 & -13.77 & -46.78 & * -5.46 \\
\hline & $\mathrm{Ce}$ & -139.63 & -10.24 & -11.54 & -43.01 & * -5.8 \\
\hline & $\operatorname{Pr}$ & -141.36 & -10.95 & -12.45 & -44.12 & -8.11 \\
\hline & $\mathrm{Nd}$ & -139.56 & -9.11 & -11.51 & -40.65 & -7.58 \\
\hline & $\mathrm{Eu}$ & -124.09 & -8.11 & & -37.39 & $* *-8.77$ \\
\hline & Dy & -139.04 & -7.79 & -9.39 & -30.8 & -9.99 \\
\hline & Er & -140.35 & -7.31 & -11.31 & -26.75 & -11.24 \\
\hline
\end{tabular}

la Familia C normalizadas a Lutita (WSA) y a la mezcla P40C60; y en la Figura 11d se grafica la mezcla P20C80 para muestras seleccionadas de la Familias A, C e I, normalizadas a Lutita (WSA).

Para la firma de P100 se consideró la distribución de concentraciones de ETR de la familia C cuya característica principal es la fuerte anomalía positiva de Eu. Se usaron los promedios para La, Ce, $\mathrm{Pr}, \mathrm{Nd}, \mathrm{Sm}, \mathrm{Gd}, \mathrm{Dy}$, Er e Yb, valores estimados para un punto medio entre los ETR contiguos de Tb, Ho, Tm y Lu, y la concentración de Eu más alta registrada en la zona de estudio (muestra 63). Para las rocas marinas se utilizó la firma de ETR con la más baja concentración de Ce del agua subterránea reportada por Johannesson et al. (2005) en la región de La Muralla.

\section{DISCUSIÓN}

\section{Familias de agua en función de las anomalías de Ce y Eu}

\section{Anomalía de cerio en el agua subterránea}

Debido a su configuración electrónica y dependiendo del $\mathrm{pH}$ y del potencial reducción-oxidación (Eh), el Ce se puede encontrar naturalmente como $\mathrm{Ce}^{3+} \mathrm{o} \mathrm{Ce}^{4+}$, este último formando la especie insoluble $\mathrm{CeO}_{2}$, (Brookins, 1983). En la Figura 12a se presenta el diagrama de fases Eh-pH del sistema Ce- $\mathrm{H}_{2} \mathrm{O}$, así como valores de $\mathrm{pH}$, mediciones y estimaciones del Eh para aguas subterráneas de diferentes partes del mundo. Aunque el Eh no fue medido durante la recolección de las muestras, en la literatura se ha reportado un amplio rango de potencial reducción-oxidación en el agua subterránea en general, con Eh desde
-0.2 V hasta 0.6 V (Noack et al., 2014). En el caso del agua subterránea en acuíferos regionales de México, los rangos son más acotados: el acuífero granular, regional de La Laguna en el norte de México, tiene un Eh entre 0.2 y $0.4 \mathrm{~V}$, utilizando diferentes parejas reducción-oxidación (Ortega-Guerrero, 2017). Tanto el $\mathrm{Ce}^{3+}$ como $\mathrm{el} \mathrm{CeO}_{2}$ son posibles fases estables en el rango de $\mathrm{pH}$ del agua subterránea de la zona de estudio, $\mathrm{y}$ ambos pueden tener cabida en el origen de las anomalías negativas de Ce. Si el Ce ${ }^{3+}$ fuese la fase estable, las anomalías de Ce serían el resultado de la interacción del agua subterránea con rocas que presentan dicha anomalía; mientras que si el $\mathrm{Ce}^{4+}\left(\mathrm{como}_{\mathrm{CeO}}\right)$ fuera la especie estable, las anomalías negativas de Ce se generarían principalmente por la incorporación de Ce en fases insolubles. Dado que el $\mathrm{Ce}^{3+}$ es la especie dominante bajo las condiciones de $\mathrm{Eh}-\mathrm{pH}$ en la mayoría de las aguas subterráneas (Figura 12a), se asume que las anomalías negativas de Ce en el agua subterránea del suroeste de Guanajuato son en mayor medida generadas por su circulación a través de materiales que presentan empobrecimiento de Ce respecto al resto de los ETR.

Las anomalías negativas de $\mathrm{Ce}$, así como un enriquecimiento en ETRP, son comunes en rocas y sedimentos de origen marino, donde

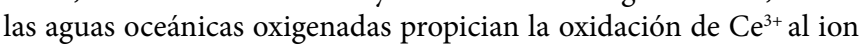
insoluble $\mathrm{Ce}^{4+}$, el cual se incorpora en nódulos de manganeso y otros óxidos e hidróxidos de Fe-Mn generando el característico empobrecimiento de Ce en el agua de mar (Goldberg et al., 1963; Piper, 1974; Elderfield y Greaves, 1982; Fleet, 1984; De Baar et al., 1985; Murray et al., 1990; Madhavaraju y González-León, 2012; Nelson et al., 2015; Munemoto et al., 2015). El enriquecimiento relativo en ETRP, por otra parte, se debe a que éstos forman complejos más estables que los ETRL (Goldberg et al., 1963; Piper, 1974). 
Se ha demostrado analíticamente que la mayoría de los sedimentos biogénicos y pelágicos de mar abierto preservan su anomalía negativa de Ce (Piper, 1974; Fleet, 1984). Las calizas adquieren la firma de ETR propia del agua de mar por la acumulación de sedimentos pelágicos y la precipitación de elementos y compuestos disueltos, mientras que los sedimentos de grano fino, a pesar de provenir mayormente de la erosión de la corteza continental, lo hacen mediante adsorción (Murray et al., 1992). Se han reportado anomalías negativas de Ce en calizas marinas desde precámbricas hasta holocénicas en diferentes partes del mundo (Kawabe et al., 1991; Webb y Kamber, 2000; Madhavaraju y González-León, 2012; Siebert et al., 2012, entre otros), en pedernal y otros sedimentos de grano fino tanto del Océano Atlántico como del Océano Pacífico (Murray et al., 1992).

Considerando lo anterior, la anomalía negativa de Ce, característica de la familia $\mathrm{A}$ en el área de estudio estaría asociada, en gran medida, a la circulación del agua subterránea a través de las rocas marinas-carbonatadas del Jurásico-Cretácico que afloran en la Sierra de Guanajuato y se encuentran en el subsuelo del Bajío, a profundidades de más de $300 \mathrm{~m}$, como parte de un conjunto de fosas tectónicas (SGM, 1997). Esto, además, indicaría que existe una componente de flujo ascendente desde el acuífero carbonatado hacia el acuífero fracturado en rocas de la SMOcc y hacia el acuífero granular. Esta componente de flujo ascendente ha sido reportada en acuíferos del norte-noreste del estado de Guanajuato y en San Luis Potosí, asociada a la influencia de los sistemas regionales de flujo de agua subterránea (Carrillo-Rivera et al., 2002; Ortega-Guerrero, 2009).

Cabe mencionar que una anomalía de Ce en agua subterránea fue reportada a $5 \mathrm{~km}$ al norte del área de estudio (Figuras 1 b y 2 ), en un campo de pozos que abastece a la Ciudad de León conocido como La Muralla (Johannesson et al., 2005). Estos autores sólo consideraron la influencia de las ignimbritas de los primeros $250 \mathrm{~m}$ de profundidad y no asociaron la anomalía negativa de Ce con las rocas marinas ubicadas estratigráficamente a mayor profundidad.

Además del predominio del $\mathrm{Ce}^{3+}$ como especie estable en el diagrama de fases Eh-pH en el rango de $\mathrm{pH}$ de las muestras de agua subterránea y la presencia de rocas con la anomalía negativa de Ce en un sistema de flujo regional, existen otros elementos que apoyan la hipótesis de que la anomalía negativa de Ce en las muestras de agua subterránea es producto de la interacción con las rocas marinas de la secuencia vulcano-sedimentaria y no de su paso por condiciones oxidantes a lo largo del camino de flujo. Estos elementos son: 1) la posición espacial de las muestras que presentan la anomalía negativa de Ce, próximas a zonas de descarga regional, donde una de las características más comunes es un potencial reducción-oxidación negativo (Tóth, 1999), 2) la falta de evidencias en el patrón de ETR de interacción con otras unidades hidrogeológicas (anomalía positiva o negativa de Eu por interacción con el material de relleno de cuenca o con las rocas de la SMOcc, respectivamente) y 3) el fuerte fraccionamiento de ETRP/ETRL.

La anomalía positiva de cerio en las muestras de las familias $\mathrm{F}$ y $\mathrm{H}$ (Figura 8f-h) puede deberse a la influencia de arcillas detríticas (Tobia y Aqrawi, 2016). Se han observado variaciones significativas en el patrón de ETR en calizas por la cantidad de material terrígeno presente (Madhavaraju y Ramasamy, 1999; Madhavaraju y GonzálezLeón, 2012; Siebert et al., 2012).

\section{Anomalía de europio en el agua subterránea}

El diagrama de estabilidad Eh-pH de Eu se presenta en la Figura $12 \mathrm{~b}$; este diagrama considera los datos de este estudio, donde el rango de variación del Eh en acuíferos regionales en el centro de México es entre 0.2 y 0.4 V (Ortega-Guerrero, 2017) y los datos de Noack et al. (2014) con muestras de agua subterránea de diferentes partes del mundo. Las
Tabla 5. Índices de saturación de algunos minerales con relevancia para las muestras seleccionadas

\begin{tabular}{lccc}
\hline \multirow{2}{*}{ Mineral } & \multicolumn{3}{c}{ Muestra } \\
\cline { 2 - 4 } & 55 & 85 & 86 \\
\hline calcita & -0.74 & -0.30 & -0.83 \\
yeso & -2.48 & -2.61 & -2.49 \\
calcedonia & 0.28 & 0.51 & 0.62 \\
caolinita & 8.72 & 8.69 & 8.73 \\
illita & 9.63 & 10.67 & 9.87 \\
Feldespato Alcalino & 4.80 & 6.09 & 5.46 \\
albita & 2.61 & 3.62 & 3.09 \\
anortita & 0.19 & 1.01 & -0.38 \\
\hline
\end{tabular}

anomalías positivas y negativas de Eu pueden tener un origen común que es la incorporación de $\mathrm{Eu}^{2+}$ en las plagioclasas cálcicas, ya que por su relación carga/radio iónico, el $\mathrm{Eu}^{2+}$ puede sustituir al $\mathrm{Ca}^{2+}$ en su estructura cristalina. Sin embargo, es demasiado grande para entrar en otras fases como los clinopiroxenos, fase presente en los magmas menos evolucionados. En la medida en que $\mathrm{el} \mathrm{Eu}^{2+}$ se incorpora a las plagioclasas, el Eu se agota en el magma respecto a los otros ETR, generando empobrecimiento en las rocas ígneas más evolucionadas (Henderson, 1984). En la zona de estudio se han reportado anomalías negativas de Eu en las rocas félsicas (Figuras 3 y 4), de las cuales las rocas de la SMOcc presentan la mayor magnitud. Las anomalías positivas de Eu, por otra parte, están presentes en las rocas de composición intermedia a máfica de la FVTM (Figura 3).

En el caso de los resultados de concentración de ETR en el agua subterránea del área de estudio, las familias de agua D, E y F (Figura 8d-8f) presentan anomalías negativas de Eu que resultarían de la interacción con el acuífero fracturado en rocas félsicas de la SMOcc. Esto es coherente con la distribución espacial de las muestras ya que, a excepción de la muestra 6 , se encuentran en la periferia próxima de la Sierra de Pénjamo (Figura 5), una zona de recarga local y cuyo núcleo está conformado por una gruesa secuencia de ignimbritas y riolitas de la SMOcc.

En el caso de la familia de agua C, caracterizada por la anomalía positiva de Eu y cuya distribución espacial es en el acuífero granular, la magnitud de la anomalía podría estar asociada a la meteorización de las plagioclasas cálcicas presentes en las rocas máficas de la FVTM que se encuentran como flujos intercalados y sedimentos clásticos que constituyen el relleno de cuenca continental. El fuerte enriquecimiento de Eu en estas muestras de agua subterránea puede ser indicativo de un largo lapso de interacción con estos sedimentos, así como de su limitado contacto con otras rocas, por lo menos con las de composición félsica. De esta manera, el movimiento de estas muestras de agua estaría asociado principalmente al acuífero granular. Cabe mencionar que no se conoce la composición mineralógica de los sedimentos que constituyen el acuífero granular y si tienen minerales que resulten en una anomalía positiva de Eu; tampoco se conoce la cantidad de plagioclasa que tienen, lo que abre un tema adicional de investigación de ETR en sedimentos de estos acuíferos.

Nelson et al. (2015) sugieren que, además de la interacción del agua con las plagioclasas de los basaltos, las anomalías positivas de Eu en el agua subterránea se deben a que estas aguas son más reductoras que otras, con lo que el $\mathrm{Eu}^{2+}$ sería más fácilmente extraído de los basaltos $\mathrm{y}$ menos adsorbido en las superficies que el $\mathrm{Eu}^{3+}$. Aunque no se cuenta con mediciones de Eh para estas aguas subterráneas, los valores de Eh reportados para estudios de comportamiento de ETR en el mundo, varían entre -0.2 y $0.6 \mathrm{~V}$ (Noack et al., 2014). Por otro lado, el rango 


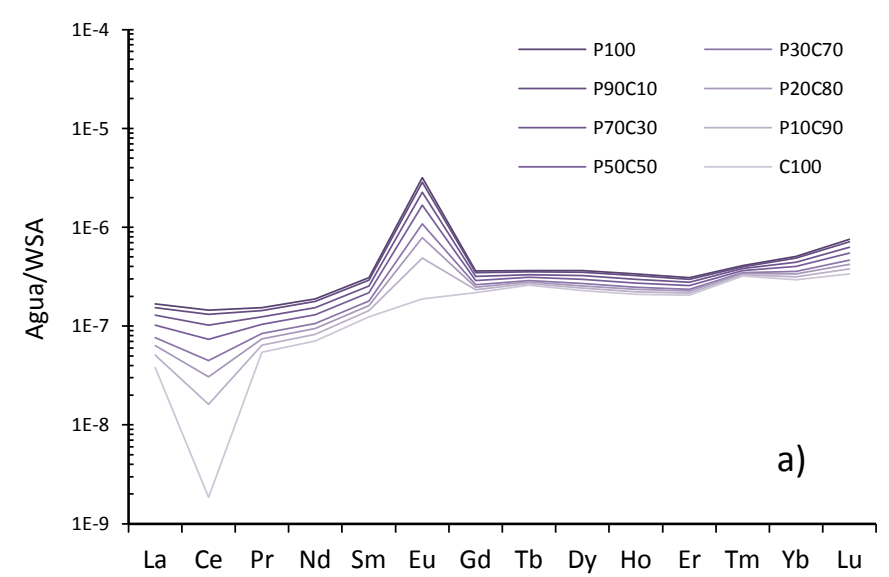

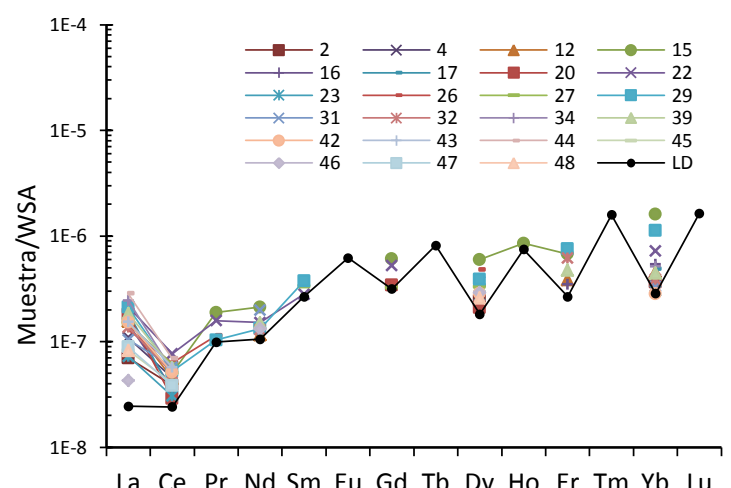

La Ce Pr Nd Sm Eu Gd Tb Dy Ho Er Tm Yb Lu

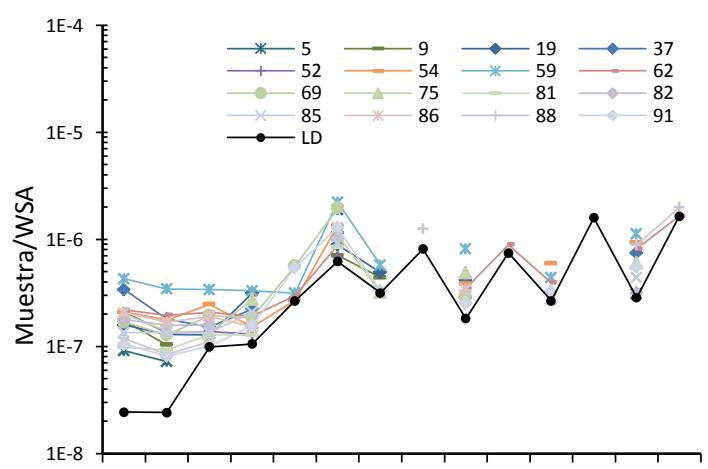

La Ce Pr Nd Sm Eu Gd Tb Dy Ho Er Tm Yb Lu

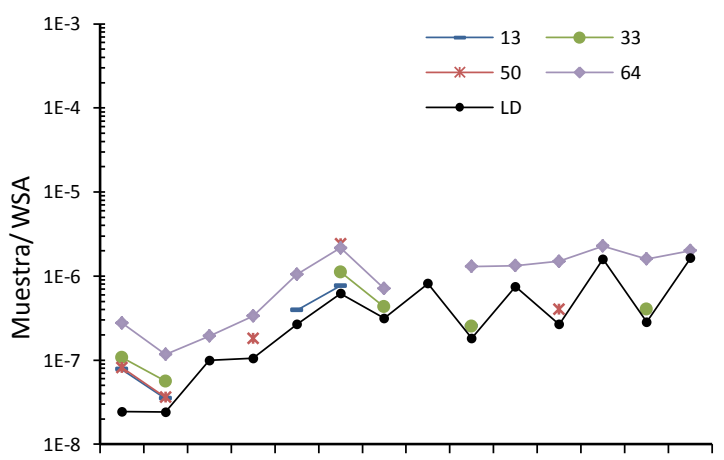

La Ce Pr Nd Sm Eu Gd Tb Dy Ho Er Tm Yb Lu

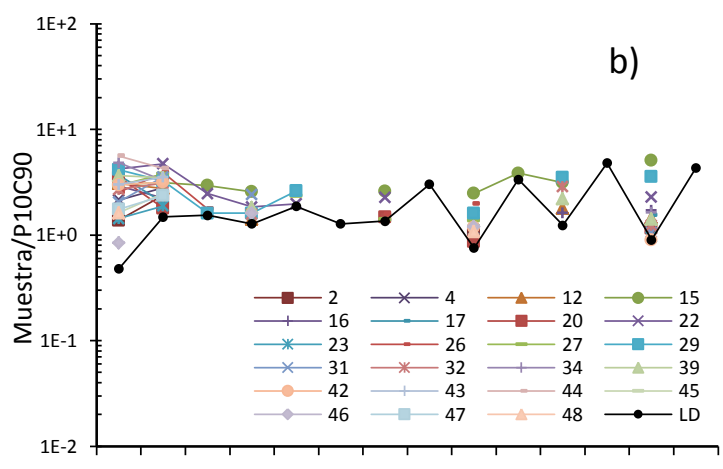

La Ce Pr Nd Sm Eu Gd Tb Dy Ho Er Tm Yb Lu

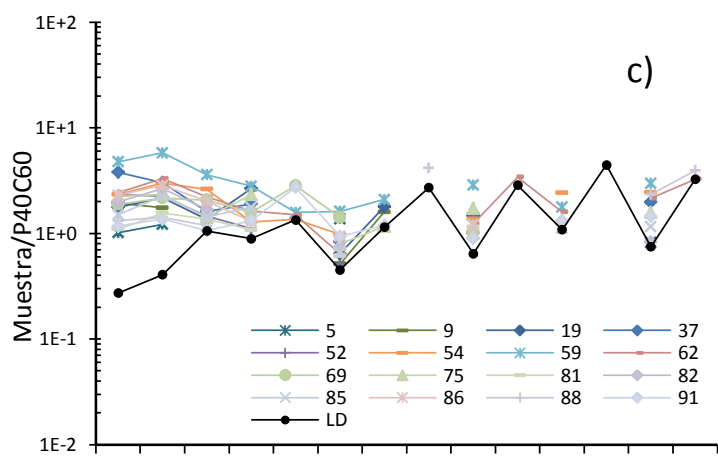

La Ce Pr Nd Sm Eu Gd Tb Dy Ho Er Tm Yb Lu

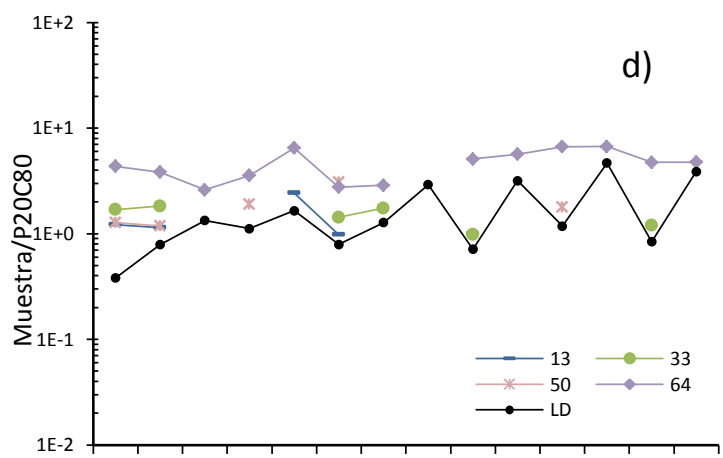

La Ce Pr Nd Sm Eu Gd Tb Dy Ho Er Tm Yb Lu

Figura 11. a) Modelización de mezclas en diferentes proporciones de agua de rocas marinas cretácicas (C100) y agua del acuífero granular (P100); b) Algunas muestras de la Familia A normalizadas al Promedio Mundial de Lutita y a la mezcla de agua en rocas marinas y material de relleno P10C90; c) Algunas muestras de la familia C normalizadas al Promedio Mundial de Lutita y a la mezcla de aguas P40C60; d) Muestras de la Familia I, muestra 13 de la familia A y muestra 33 de la familia C normalizadas al Promedio Mundial de Lutita y a la mezcla de aguas P20C80. 
de variación en acuíferos regionales en el centro de México, entre 0.2 y $0.4 \mathrm{~V}$ (Ortega-Guerrero, 2017), sugiere que este proceso no sería factible en el rango de variación de $\mathrm{pH}$ de estas aguas. En otros sitios se ha visto que las anomalías positivas de Eu son características de aguas subterráneas que han estado en contacto con rocas de composición máfica a intermedia (Banks et al., 1999; Nelson et al., 2015).

\section{Procesos que controlan la concentración, especiación y fraccionamiento de ETR en el agua subterránea}

La abundancia de ETR en el agua subterránea aumenta con la fuerza iónica, porque hay mayor cantidad de iones en solución compitiendo por una cantidad limitada de sitios en las superficies de los minerales, es decir, disminuye la adsorción de ETR. Teniendo en cuenta que las especies carbonatadas con carga positiva son más susceptibles a ser adsorbidas en las superficies minerales por su carga negativa, esta relación es más fácilmente perceptible en los ETRL por su ligera tendencia a formar más $\mathrm{LnCO}_{3}{ }^{+}$que los ETRP. De esta manera, la fuerza iónica puede favorecer o atenuar el fraccionamiento de los ETR. La concentración de ETRL y la relación ETRP/ETRL contra la fuerza iónica de las muestras analizadas en la especiación indica que la concentración de ETRL en solución es más alta a mayor fuerza iónica, tal como lo mencionan Noack et al. (2014). Además, y coherente con lo anterior, el grado de fraccionamiento ETRP/ETRL es menor a medida que aumenta la fuerza iónica.

Desde el punto de vista hidrogeológico, la disminución de la fuerza iónica en el sentido de flujo daría lugar a un aumento de la capacidad de adsorción, principalmente de $\mathrm{LnCO}^{+}$, especie acuosa de ETR más abundante, sobre todo en los ETRL (Figuras 11a-11c). $\mathrm{Al}$ ser removidos más ETRL que ETRP de la solución, se genera un enriquecimiento relativo de ETRP en el agua. Como se verá más adelante, esto concuerda con el hecho de que constantemente se están formando arcillas producto de la disolución de feldespatos. La carga negativa permanente de las arcillas y de las superficies en los materiales granulares de los acuíferos favorece la adsorción de especies de ETR cargadas positivamente en su superficie (Johannesson et al., 1997). En países como China, las arcillas lateríticas corresponden a una de las principales menas de ETR (Papangelakis y Moldoveanu, 2014) y la adsorción en diferentes materiales es utilizada como un mecanismo de recobro (Anastopoulos et al., 2016).

El rango de variación del $\mathrm{pH}$ en la zona de estudio (Figura 9a) y la concentración de ETR en solución, son consistentes con los valores reportados por Noack et al. (2014) (Figura 9b). El potencial de hidrógeno $(\mathrm{pH})$ es el parámetro que ejerce mayor control en la concentración de ETR disueltos; en términos generales, las aguas más ácidas tienen un mayor contenido de ETR en solución, posiblemente producto de una meteorización intensificada debida a la acidificación y/o por la mayor abundancia de ETR en la roca fuente de carácter félsico. En contraste, en aguas más básicas, los ETR tienden a coprecipitar y ser adsorbidos (Noack et al., 2014), por lo que su concentración en solución tiende a disminuir, tal como se ve reflejado en las muestras de agua subterránea de la zona y de diferentes lugares del mundo (Figura 9b).

El pH controla también la especiación de los ETR en solución (Sikakwe et al., 2016). Las especies más abundantes de las muestras 56, $93,55,7,36,6$ y 85 , cuyos valores respectivos de $\mathrm{pH}$ son $5.9,6.38,7.12$, $7.25,7.47,7.72$ y 8.08 , cubren de manera homogénea el rango de $\mathrm{pH}$ del agua de la zona de estudio: se puede comprobar cómo ligeros cambios de $\mathrm{pH}$ influyen en la proporción de los diferentes complejos (Figuras 11a-11d). La especie dominante para todos los ETR con pH ácido y circumneutrales es el carbonato $\mathrm{LnCO}_{3}{ }^{+}$, y a medida que aumenta el $\mathrm{pH}$, la abundancia de las especies de bicarbonato $\mathrm{Ln}(\mathrm{CO} 3)_{2}^{-}$aumenta considerablemente, llegando a ser el ligando más abundante para los ETRP. En el caso de los ETR como iones libres $\mathrm{Ln}^{+3}$, su abundancia
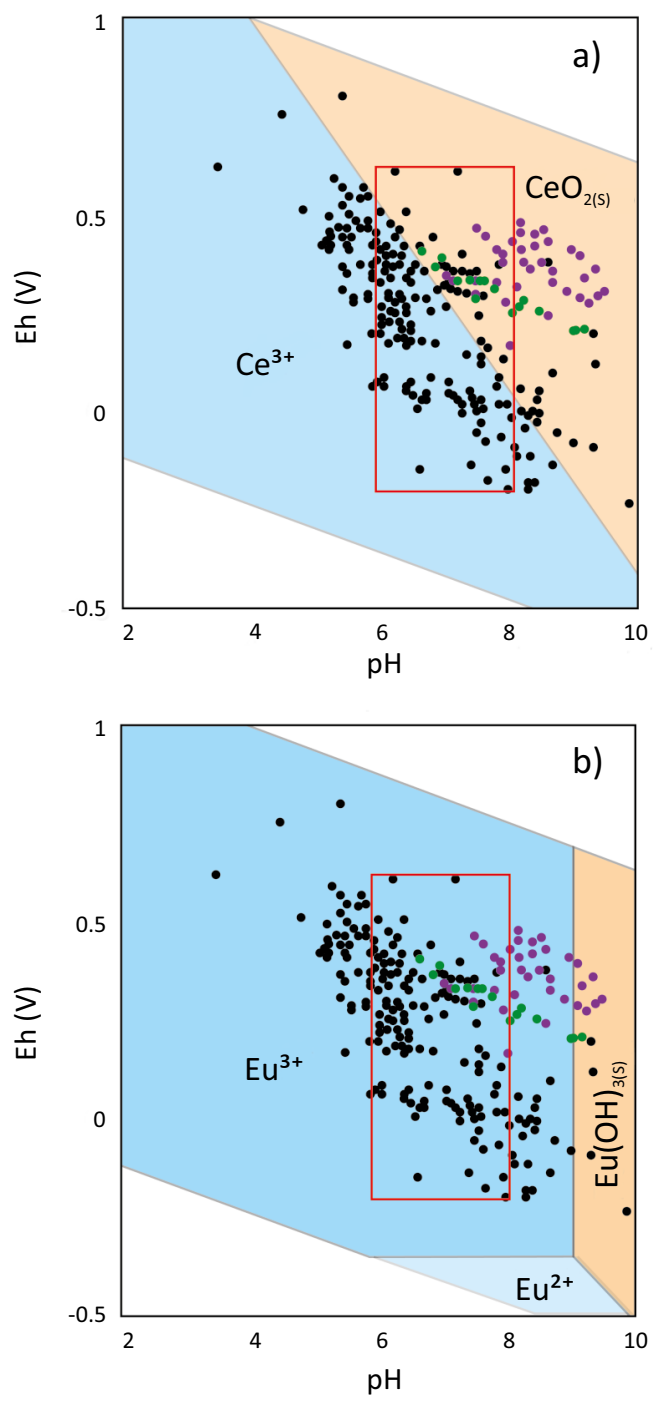

Figura 12. a) Diagrama de estabilidad potencial reducción-oxidación (Eh) - $\mathrm{pH}$ para especies relevantes en el sistema $\mathrm{Ce}-\mathrm{H}_{2} \mathrm{O}$ a $25{ }^{\circ} \mathrm{C}$ y 1 bar de presión. b) Diagrama de estabilidad potencial reducción-oxidación (Eh) - $\mathrm{pH}$ para especies relevantes en el sistema Eu- $\mathrm{H}_{2} \mathrm{O}$ a $25^{\circ} \mathrm{C}$ y 1 bar de presión. Modificado de Noack et al. (2014), original de Brookins (1983). El rectángulo rojo limita el rango de $\mathrm{pH}$ en la zona de estudio (5.90-8.08) y el rango de Eh medido en aguas subterráneas en diferentes estudios recopilados por Noack et al. (2014). Los círculos negros son las muestras de agua subterránea, los círculos morados son mediciones tomadas de Robertson (1989) y los círculos verdes son valores de Eh estimados de muestras de agua de La Laguna presentadas por Ortega-Guerrero (2017).

es mayor en los ETRL y su cantidad disminuye gradualmente con el aumento de $\mathrm{pH}$. Además, para $\mathrm{pH}$ básico, las especies carbonatadas siempre cubren un mayor porcentaje de la especiación de los ETRL que en las de los ETRP, en oposición a las especies bicarbonatadas, cuyo porcentaje de especiación es mayor en los ETRP que en los ETRL para todo el rango de $\mathrm{pH}$ de estas aguas subterráneas (Figura 10d). Como se verá a continuación, este comportamiento diferencial de las especies de ETR tiene importantes implicaciones en el fraccionamiento del patrón de ETR.

La relación $\mathrm{Yb}_{\mathrm{NS}} / \mathrm{Nd}_{\mathrm{NS}}$ y la pendiente, generalmente positiva, en los patrones de ETR de las muestras de agua normalizados al Promedio Mundial de Lutita representan un enriquecimiento de los ETRP relativo a los ETRL. El principio de este comportamiento puede ser explicado a 
partir de la complejación de los ETR disueltos en el agua subterránea, tema que será desarrollado en el siguiente apartado.

El efecto del $\mathrm{pH}$ en el fraccionamiento de ETRL y ETRP depende de la alcalinidad del agua: cada uno de los ETR tiende a formar complejos en diferentes proporciones con los ligandos que están disueltos. Por ejemplo, a pH mayores a 7, los ETRP forman una mayor cantidad de bicarbonatos (ETRP $\left(\mathrm{CO}_{3}\right)_{2}{ }^{-}$) y una menor proporción de carbonatos $\left(\right.$ ETRP $\mathrm{CO}_{3}^{+}$) que los ETRL (Figura 10d). Esto da lugar al fraccionamiento de los ETRL y los ETRP mediante dos mecanismos: por una parte, los complejos que incorporan a los ETRP son más solubles que los complejos de ETRL (Goldberg et al., 1963; Piper, 1974; Nelson et al., 2015) y, por otra parte, la carga iónica de los complejos formados puede facilitar o inhibir su adsorción en las superficies de los materiales acuíferos (Goldberg et al., 1963; Munemoto et al., 2015).

Debido al predominio de los complejos con carga positiva en los ETRL ( $\mathrm{LnCO}_{3}{ }^{+}$principalmente), éstos son preferiblemente adsorbidos en los sitios de las superficies con carga negativa del material granular del acuífero, comunes en condiciones de aguas carbonatadas y con $\mathrm{pH}$ neutro a ligeramente alcalino (Johannesson et al., 1997; Nelson et al., 2015; Munemoto et al., 2015), induciendo de esta manera un enriquecimiento relativo de los ETRP en el agua subterránea. Además de las rocas y minerales, los ETR pueden ser adsorbidos en la superficie de partículas y coloides que estén siendo transportados en suspensión en el agua. Nelson et al. (2015) demostraron experimentalmente que muestras de agua filtradas tenían una menor concentración total de ETR que las mismas muestras sin filtrar.

Un parámetro que puede ser usado en la estimación relativa del grado de adsorción de los ETR en los sitios de adsorción es la fuerza iónica ya que, como se vio anteriormente, un aumento de la fuerza iónica conlleva a una disminución de la capacidad de adsorción de los ETR (Munemoto et al., 2015). La concentración y especiación de los ETR, depende de los cambios de $\mathrm{pH}$ en la zona de estudio. Si bien, la formación de los complejos de carbonato libera iones hidrógeno a la solución, de acuerdo a las reacciones:

$$
\begin{gathered}
\mathrm{Ln}^{+3}+\mathrm{HCO}_{3}^{-}=\mathrm{LnCO}_{3}{ }^{+}+\mathrm{H}^{+} \\
\mathrm{Ln}^{+3}+2 \mathrm{HCO}_{3}^{-}=\mathrm{Ln}\left(\mathrm{CO}_{3}\right)_{2}{ }^{-}+2 \mathrm{H}^{+}
\end{gathered}
$$

Las concentraciones tan bajas de los ETR en el agua subterránea (del orden de picomoles a algunos nanomoles por litro) no provocan un aumento considerable en la actividad de $\mathrm{H}^{+}$y por tanto tampoco generan una disminución significativa del $\mathrm{pH}$. En cambio, uno de los mecanismos que puede contribuir en el aumento del $\mathrm{pH}$, que es viable desde el punto de vista hidrogeológico de la zona y que concuerda con los índices de saturación de feldespatos y arcillas en las muestras de agua analizadas (Tabla 4), es una disolución intensificada de feldespatos, bajo las reacciones:

$$
\begin{gathered}
\mathrm{KAlSi}_{3} \mathrm{O}_{8}+2 \mathrm{H}^{+}+9 \mathrm{H}_{2} \mathrm{O}=2 \mathrm{~K}^{+}+\mathrm{Al}_{2} \mathrm{Si}_{2} \mathrm{O}_{5}(\mathrm{OH})_{4}+4 \mathrm{H}_{4} \mathrm{SiO}_{4} \\
\mathrm{NaAlSi}_{3} \mathrm{O}_{8}+2 \mathrm{H}^{+}+9 \mathrm{H}_{2} \mathrm{O}=2 \mathrm{Na}^{+}+\mathrm{Al}_{2} \mathrm{Si}_{2} \mathrm{O}_{5}(\mathrm{OH})_{4}+4 \mathrm{H}_{4} \mathrm{SiO}_{4} \\
\mathrm{CaAl}_{2} \mathrm{Si}_{2} \mathrm{O}_{8}+2 \mathrm{H}^{+}+\mathrm{H}_{2} \mathrm{O}=\mathrm{Ca}^{2+}+\mathrm{Al}_{2} \mathrm{Si}_{2} \mathrm{O}_{5}(\mathrm{OH})_{4}
\end{gathered}
$$

De esta manera, el pH ligeramente alcalino en la mayoría de las muestras de agua de la zona de estudio probablemente se debe a la intensa disolución de los feldespatos de las rocas volcánicas de la SMOcc y la FVTM, y de los depósitos de relleno provenientes de su erosión. Por lo tanto, es de esperarse que, a mayor grado de interacción con estas rocas, mayor sea la alcalinidad del agua subterránea. Esta generalización puede ser vista en las Figuras 10a-10d, donde la muestra más ácida (55) se encuentra más próxima a la zona de recarga en los caminos de flujo que viajan a través de las ignimbritas oligocénicas; en contraste, la muestra más alcalina (85) posiblemente ha atravesado un extenso camino de flujo a lo largo del cual ha tenido un alto grado de interacción principalmente con los sedimentos cenozoicos, provenientes de la erosión y meteorización de las rocas volcánicas.

\section{Modelo conceptual del Sistema de Flujo de Agua Subterránea (SFAS)}

Con todo lo anterior, se propone un modelo conceptual del funcionamiento del agua subterránea, a partir de la interacción con las diferentes unidades rocosas en el Bajio de Guanajuato, en el que se explicarían los patrones de ETR observados en el agua subterránea del área de estudio, bajo el concepto de SFAS (Freeze y Witherpoon, 1966,1967, 1968; Ortega-Guerrero y Farvolden, 1989; Tóth, 1999; Morales-Casique et al., 2016). Tales patrones se muestran en las secciones hidrogeológicas esquemáticas de las Figuras 13 y 14.

\section{Sistemas de flujo regionales}

Estos sistemas se evidencian principalmente en las muestras de agua subterránea de la familia A e I, que se encuentran en o muy próximas a zonas de descarga regional como son el Río Turbio y el Río Lerma (Secciones C-C' y D-D' de la Figura 13). La anomalía negativa de Ce y los bajos contenidos totales de ETR (33 a 244 pmol/ $\mathrm{kg}$ ) en las muestras de la familia A indican un flujo de tipo regional al interactuar con las rocas marinas de la secuencia vulcano-sedimentaria. Sin embargo, en muchas de las muestras la temperatura y el contenido de $\mathrm{Li}^{+}$registrados no concuerdan con esta interpretación al ser relativamente bajos ( 20 a $34{ }^{\circ} \mathrm{C}$ y de 0.015 a $0.13 \mathrm{mg} / \mathrm{L}$, respectivamente). Esta discrepancia puede deberse a la mezcla con aguas subterráneas más someras durante el bombeo. Dentro de la familia A, la muestra 48, tomada en las proximidades de la Sierra de Abasolo, es la que presenta la temperatura más alta $\left(47^{\circ} \mathrm{C}\right)$, un alto contenido de $\mathrm{Li}^{+}(0.29 \mathrm{mg} / \mathrm{L})$ y el contenido más bajo de ETR (alto grado de fraccionamiento), indicando un largo camino de flujo que circula a gran profundidad (Carrillo-Rivera et al., 2002).

Las muestras de la familia I, que presentan la anomalía negativa de Ce, sugieren circulación profunda a través de rocas de la secuencia vulcano-sedimentaria. Adicionalmente, presentan una anomalía positiva de gran magnitud de Eu que también sugiere la interacción con el relleno vulcano-clástico de la cuenca, un contenido significativo de ETR (de hasta $493 \mathrm{pmol} / \mathrm{kg}$ ), temperatura relativamente baja $\left(20-22{ }^{\circ} \mathrm{C}\right)$, y bajo contenido de $\mathrm{Li}^{+}(0.025 \mathrm{a} 0.047 \mathrm{mg} / \mathrm{L})$ que podrían representar la mezcla con aguas subterráneas más someras que circulan a través de sistemas de flujo locales.

La elevada temperatura $\left(56{ }^{\circ} \mathrm{C}\right)$, la alta concentración de $\mathrm{Li}^{+}$ ( $0.33 \mathrm{mg} / \mathrm{L})$, el bajo contenido de ETR $(243 \mathrm{pmol} / \mathrm{kg}$ ) y el fuerte fraccionamiento de ETRP/ETRL $\left(\mathrm{Yb}_{\mathrm{NS}} / \mathrm{Nd}_{\mathrm{NS}}\right.$ de 5.99) en la muestra 35 de la familia B, sugiere circulación profunda y largas distancias de recorrido (Davies et al., 1985; Tóth, 1999; Carrillo-Rivera et al., 2002). El patrón de ETR, además, indica interacción con las rocas intermedias a máficas de la FVTM, posiblemente durante el flujo ascendente.

\section{Sistemas de flujo intermedios}

Estos sistemas están representados en muestras de agua que indican circulación a través de rocas félsicas de la SMOcc, basaltos y andesitas de la FVTM, y de depósitos fluviales-lacustres que rellenan la cuenca, localizados muy cerca de los cauces de los ríos Turbio y Lerma. Se incluyen algunas muestras de las familias B y C con un contenido relativamente bajo de ETR ( 50 a $395 \mathrm{pmol} / \mathrm{kg}$ ) y alto grado de fraccionamiento ETRP/ETRL ( $\mathrm{Yb}_{\mathrm{NS}} / \mathrm{Nd}_{\mathrm{NS}}$ de hasta 4.5), temperaturas bajas a intermedias $\left(22\right.$ a $\left.38{ }^{\circ} \mathrm{C}\right)$ y concentraciones de $\mathrm{Li}^{+}$de bajas a altas $(0.01$ a $0.41 \mathrm{mg} / \mathrm{L})$. Estas características, en conjunto, indican circulación de flujos considerablemente larga, mas no profundos, de 
NW

SE

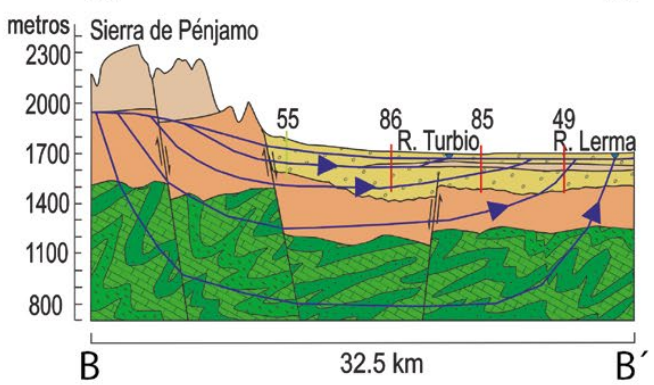

$\mathrm{N}$

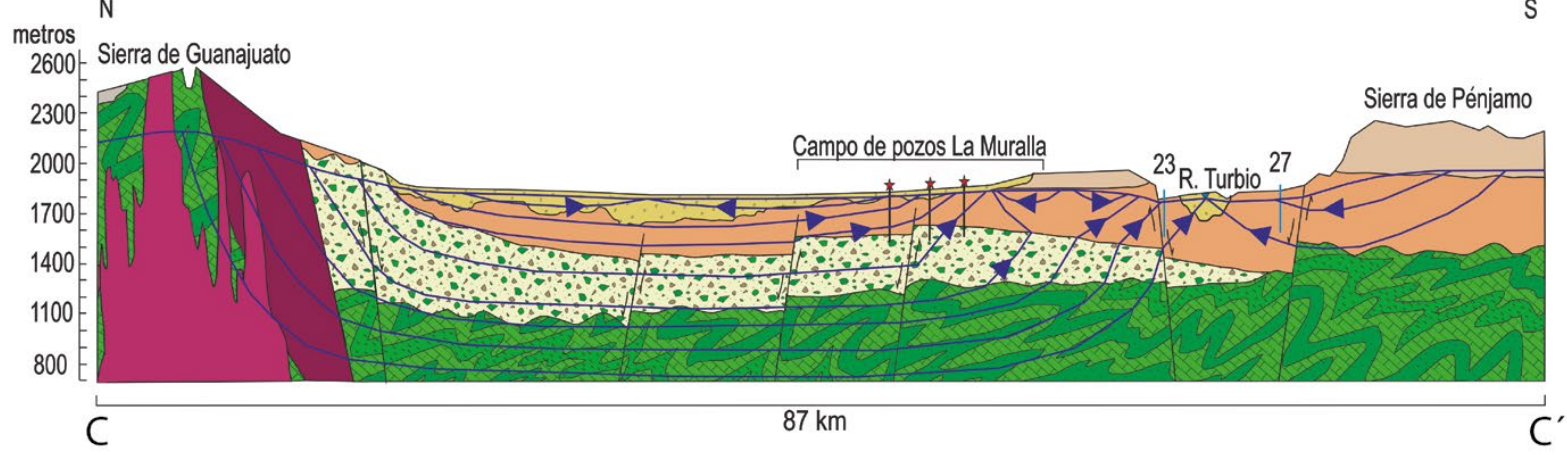

SW

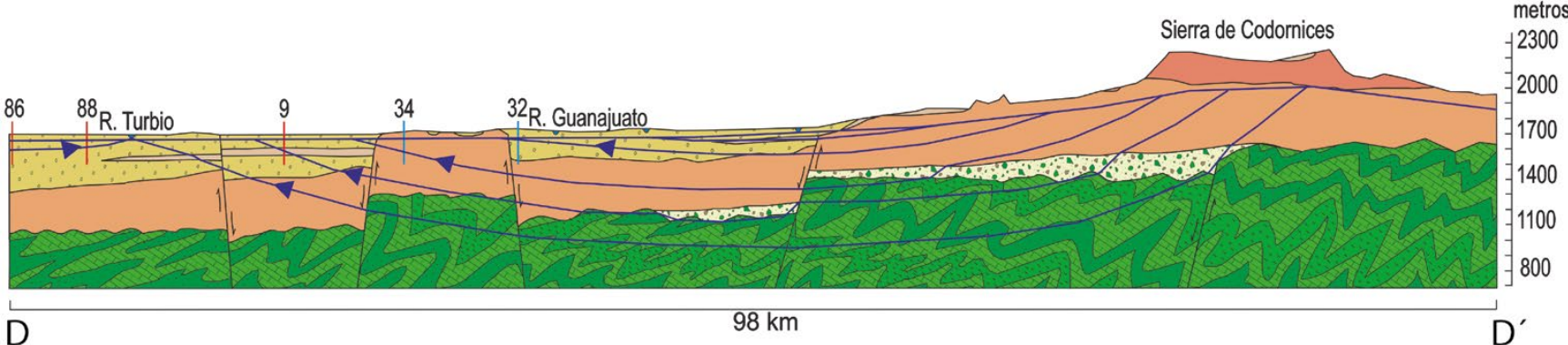

Figura 13. Secciones hidrogeológicas esquemáticas con líneas de flujo definidas a partir de la interacción agua-roca deducida a partir de los patrones de ETR en el agua subterránea. La localización de estas secciones se encuentra en la Figura 2.

acuerdo con la posición de las rocas con las que interactúan (Davies et al., 1985; Tóth, 1999; Carrillo-Rivera et al., 2002). La muestra 6 de la familia E y la muestra 25 de la familia F presentan una temperatura y concentración de $\mathrm{Li}^{+}$similares a las anteriores $\left(31\right.$ y $29^{\circ} \mathrm{C}$, y 0.21 y $0.15 \mathrm{mg} / \mathrm{L}$, respectivamente), pero la elevada concentración de ETR (784 y 2035 pmol $/ \mathrm{kg}$ ) y la anomalía negativa de Eu implican mayor interacción con las rocas félsicas de la SMOcc y, por tanto, circulación un poco más profunda.

\section{Sistemas de flujo locales}

Este sistema de flujos está reflejado en las muestras de las familias D, B y C, ubicadas principalmente sobre, o muy próximas, a las pequeñas sierras del sur del área de estudio. Las muestras de las familias B y C presentan temperaturas bajas $\left(20 \mathrm{a} 32^{\circ} \mathrm{C}\right)$, contenidos $\mathrm{de}^{+} \mathrm{i}^{+}$de bajos a altos $(0.01$ a $0.32 \mathrm{mg} / \mathrm{L})$ y concentraciones de ETR de hasta $564 \mathrm{pmol} / \mathrm{kg}$, rangos esperados en flujos relativamente cortos a través de las rocas de la FVTM y de los depósitos que rellenan la cuenca. A diferencia de las anteriores, las muestras 18 y 24 de la familia E y las muestras de la familia D presentan concentraciones muy bajas de $\mathrm{Li}^{+}(0.01 \mathrm{a}$ $0.08 \mathrm{mg} / \mathrm{L}$ ) y los más altos contenidos de $\operatorname{ETR}$ (969 a $12577 \mathrm{pmol} / \mathrm{kg}$ ), generados por la interacción temprana con las rocas de la SMOcc en la Sierra de Pénjamo y una corta longitud de los flujos.

Finalmente, el modelo conceptual de la Figura 14, resume los patrones de ETR esperados en varios sitios a lo largo de la dirección de flujo para los diferentes Sistemas de Flujo de Agua Subterránea propuestos. La evolución de los patrones de ETR, al igual que la composición química del agua es determinada en gran medida por el orden de encuentro con las unidades hidrogeológicas (Palmer y Cherry, 1984). En la Figura 14, el Patrón 1, expresa un contenido relativamente alto de ETR con una pronunciada anomalía de Ce y un fraccionamiento alto de ETRP/ETRL. En el Patrón 2, se preserva la anomalía negativa de $\mathrm{Ce}$, aumenta el fraccionamiento ETRP/ETRL y disminuye la concentración total de ETR. En el Patrón 3, se mantiene la anomalía negativa de Ce; podría interpretarse una anomalía positiva de Eu por mezcla de aguas, mientras que el fraccionamiento ETRP/ ETRL es muy alto y la concentración de ETR, muy baja. El Patrón 4, indica una concentración alta de ETR, una anomalía negativa de Eu muy pronunciada y un fraccionamiento de ETRP/ETRL muy bajo. El Patrón 5, muestra una concentración de ETR muy alta, una anomalía de negativa de Eu muy pronunciada y un fraccionamiento ETRP/ETRL 


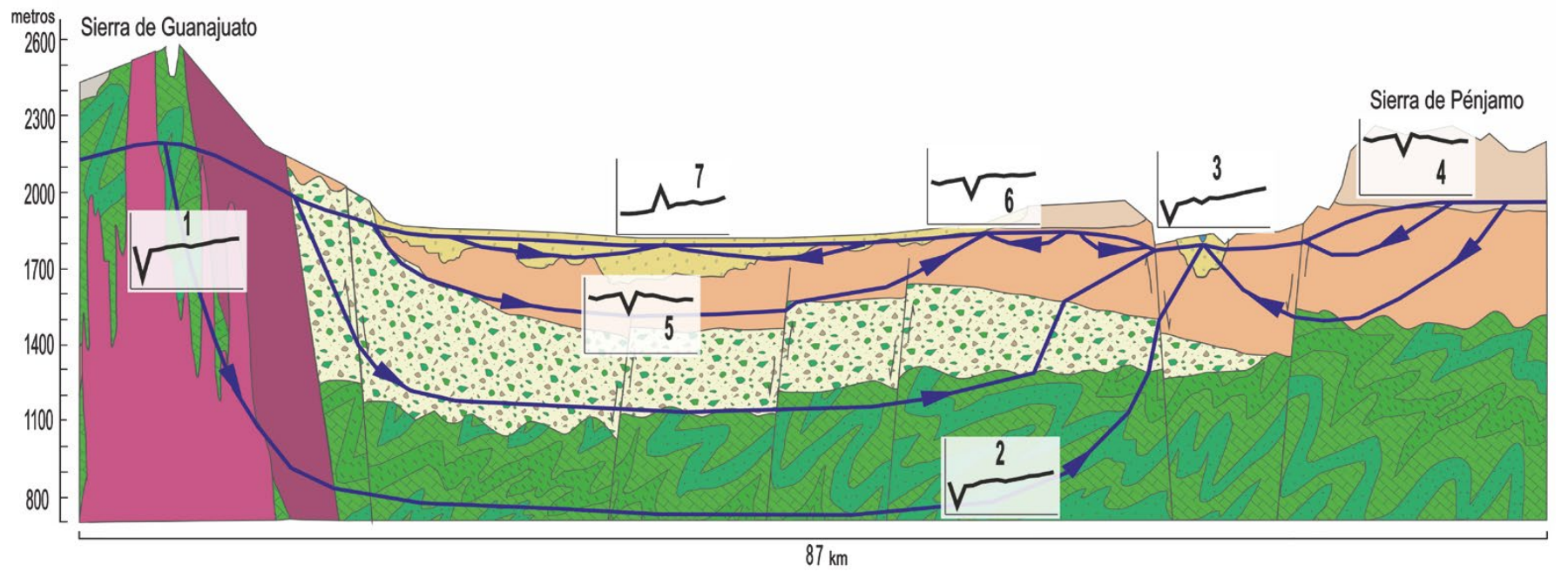

Figura 14. Patrones de ETR en agua subterránea esperados en diferentes posiciones a lo largo de los caminos de flujo para los diferentes sistemas de flujo en una sección hidrogeológica esquemática. Los patrones 1,2 y 3 corresponden a un sistema de flujo regional donde el agua circula fundamentalmente a través de la secuencia marina cretácica. Los patrones 4,5 y 6 muestran un sistema de flujo intermedio, donde el agua interactúa básicamente con las ignimbritas y riolitas de la SMOcc. El patrón 7 pertenece a un sistema de flujo local que se desarrolla en los depósitos vulcanoclásticos cenozoicos que rellenan la cuenca.

muy bajo. El Patrón 6, indica una concentración total de ETR alta, una anomalía de Eu pronunciada y un fraccionamiento de ETRP/ETRL incipiente. Finalmente, el Patrón 7, revela una concentración baja de ETR, una pronunciada anomalía de Eu y un elevado fraccionamiento de ETRP/ETRL asociado a la presencia de arcillas.

\section{CONCLUSIONES}

Los diferentes tipos de roca presentes en la zona de estudio tienen patrones de ETR característicos. Las rocas de la SMOcc presentan una pronunciada anomalía negativa de $\mathrm{Eu}$, que es significativamente de mayor magnitud en la secuencia superior y un ligero enriquecimiento en los ETRP. Por el contrario, las rocas de la FVTM muestran una pequeña anomalía positiva de Eu y un fraccionamiento de ETRL y ETRP prácticamente pequeño.

Las 94 muestras de agua subterránea analizadas fueron agrupadas en nueve familias de acuerdo al sentido y magnitud de las anomalías de $\mathrm{Ce}$ y Eu, en menor medida por el fraccionamiento ETRP/ETRL y por la concentración de ETR. Las especies inorgánicas más abundantes de ETR en el agua subterránea son los carbonatos $\mathrm{LnCO}_{3}{ }^{+}$y $\mathrm{Ln}\left(\mathrm{CO}_{3}\right)_{2}$. La abundancia de los complejos de $\mathrm{LnCO}_{3}{ }^{+}, \mathrm{LnSO}_{4}{ }^{+} \mathrm{y} \mathrm{Ln}^{3+}$ disminuye paulatinamente con el aumento del número atómico, es decir hacia los ETRP, mientras que los complejos de $\operatorname{Ln}\left(\mathrm{CO}_{3}\right)_{2}{ }^{-}$son más abundantes en los ETRP y disminuyen gradualmente hacia los ETRL. La abundancia relativa de los diferentes complejos que forman los ETR varía en función del pH. En general, en aguas más alcalinas, la fracción de los $\mathrm{Ln}\left(\mathrm{CO}_{3}\right)_{2}{ }^{-}$aumenta, y la fracción de los $\mathrm{LnCO}_{3}{ }^{+} \mathrm{y} \mathrm{Ln}^{3+}$ disminuye.

Las familias de agua adquieren su firma de ETR a partir de la interacción con rocas de la SMOcc, y con basaltos y andesitas de la FVTM. Las muestras de agua subterránea que exhiben anomalías negativas de Ce y enriquecimiento relativo de los ETRP, representan parte de un sistema de flujo regional en el que el agua interactúa con las rocas marinas de la secuencia vulcano-sedimentaria del Cretácico. Esto sugiere la continuidad hidráulica entre ellos a través de fallas y fracturas conectadas a profundidades mayores a $1000 \mathrm{~m}$, resultados que son consistentes con los modelos Tóthianos-Freezeanos de los
Sistemas de Flujo Gravitacionales de Agua Subterránea y señala la importancia de estos componentes de flujo regional en la gestión de acuíferos en el Bajío.

\section{AGRADECIMIENTOS}

El financiamiento del proyecto fue a través del Convenio UNAMConsejo Regional para el Desarrollo del Suroeste de Guanajuato, denominado "Estudio hidrogeológico de la región IV, suroeste de Guanajuato, que integra los municipios de Abasolo, Manuel Doblado, Cuerámaro, Huanímaro, Pénjamo, Pueblo Nuevo y Valle de Santiago, 2000", en particular al M.D.R. Everardo Rodríguez y J.L. Nieto Montoya. Se agradece la beca CONACYT de maestría a Tatiana Salinas-Reyes y se extiende el agradecimiento al Dr. Ángel Nieto por su apoyo en la elaboración de las secciones hidrogeológicas y a dos revisores anónimos cuyas observaciones permitieron mejorar el documento.

\section{REFERENCIAS}

Aguillón-Robles, A., Tristán-González, M., Aguirre-Díaz, G.J., Bellon, H., 2009, Syn-extensional intra-plate trachydacite-rhyolitic dome volcanism of the Mesa Central, southern Sierra Madre Occidental volcanic province, Mexico: Journal of Volcanology and Geothermal Research, 187, 33-52.

Alaníz-Álvarez, S.A., Nieto-Samaniego, A.F., Reyes-Zaragoza, M.A., OrozcoEsquivel, M.T., Ojeda-García, A.C., Vasallo, L.F., 2001, Estratigrafía y deformación extensional en la región San Miguel de Allende-Querétaro, México: Revista Mexicana de Ciencias Geológicas, 18(2), 129-148.

Anastopoulos, I., Bhatnagar, A., Lima, E.C., 2016, Adsorption of rare earth metals: A review of recent literature: Journal of Molecular Liquids, 221, 954-962.

Aranda-Gómez, J.J., Godchaux, M.M., Aguirre-Díaz, G.J., Bonnichsen, B., Martínez-Reyes, J., 2003, Three Superimposed Volcanic Arcs in the Southern Cordillera -From the Early Cretaceous to the Miocene, Guanajuato, México: Universidad Nacional Autónoma de México, Instituto de Geología, Publicación Especial 1, Field trip 6, 123-168.

Banks, N.D., Hall, G., Reimanna, C., Siewers, U., 1999, Distribution of rare earth elements in crystalline bedrock groundwaters: Oslo and Bergen regions, 
Norway: Applied Geochemistry, 14, 27-39.

Biddau, R., Bensimon, M., Parriaux, A., 2009, Rare Earth Elements in groundwater from different Alpine aquifers: Chemie der Erde, 69, 327-339.

Botero-Santa, P.A., Alaníz-Álvarez, S.A., Nieto-Samaniego, A.F., LópezMartínez, M., Levresse, G., Xu, S., Ortega-Obregón, C., 2015, Origen y desarrollo de la cuenca El Bajío en el sector central de la Faja Volcánica Transmexicana: Revista Mexicana de Ciencias Geológicas, 32(1), 84-98.

Brookins, D.G., 1983, Eh-pH diagrams for the rare earth elements at $25^{\circ} \mathrm{C}$ and one Bar Pressure: Geochemical Journal, 17, 223-229.

Carrillo-Rivera, J.J., Cardona, A., Edmunds, W.M., 2002, Use of abstraction regime and knowledge of hydrogeological conditions to control highfluoride concentration in abstracted groundwater: San Luis Potosí basin, Mexico: Journal of Hydrology, 261, 24-47.

Cerca-Martínez., L.M., Aguirre-Díaz, G.J., López-Martínez, M., 2000, The Geologic Evolution of the Southern Sierra de Guanajuato, México: A Documented Example of the Transition from the Sierra Madre Occidental to the Mexican Volcanic Belt: International Geology Review, 42, 131-151.

CEAG (Comisión Estatal del Agua de Guanajuato), 2001, Estudio hidrogeológico y modelo matemático del acuífero de Pénjamo-Abasolo, Guanajuato: Guanajuato, México, Comisión Estatal del Agua,116 pp.

CONAGUA (Comisión Nacional del Agua) 2002, Determinación de la disponibilidad de agua en el acuífero Irapuato-Valle, (1119), Estado de Guanajuato, México. https://www.gob.mx/cms/uploads/attachment/ file/103029/DR_1119.pdf, consultado en agosto de 2016.

Davies, S.N., Campbell, D.J., Bentley, H.W., Flynn, T., 1985, An introduction to groundwater tracers: Tucson, Arizona, United States of America, Department of Hydrology and Water Resources, University of Arizona, 219 pp.

De Baar, H.J.W., Bacon, M.P., Brewer, P.G., 1985, Rare earth elements in the Pacific and Atlantic Oceans: Geochimica et Cosmochimica Acta, 49, 1943-1959.

Elderfield, H., Greaves, M.J., 1982, Rare earth elements in seawater: Nature, 296, 214-219.

Ferrari, L., 2003, Digital Cartography of the Trans-Mexican Volcanic Belt: disponible en ftp://rock.geosociety.org/pub/reposit/2004/2004012.pdf, consultado en agosto de 2016.

Ferrari, L., Garduño, V.H., Innocenti, F., Manetti, P., Pasquarè, G., Vaggelli, G., 1994, A widespread mafic volcanic unit at the base of the Mexican Volcanic Belt between Guadalajara and Querétaro: Geofísica Internacional, (33)1, 107-123.

Ferrari, L., Pasquarè, G., Venegas-Salgado, S., Romero-Ríos, F., 1999, Geology of the western Mexican Volcanic Belt and adjacent Sierra Madre Occidental and Jalisco block en Delgado-Granados, H., Aguirre-Díaz, G. and Stock, J. (editors) Cenozoic tectonics and volcanism of Mexico: Geological Society of America Special Paper, 334, 65-84.

Ferrari, L., Orozco-Esquivel, M.T., Manea, V., Manea, M., 2012, The dynamic history of the TransMexican Volcanic Belt and the Mexico subduction zone: Tectonophysics, 522-523, 122-149.

Fleet, A.J., 1984, Aqueous and sedimentary geochemistry of rare earth elements en Henderson, P. (ed.), Rare Earth Element Geochemistry: Developments in Geochemistry, 2, 343-373.

Freeze, R.A., Witherspoon, P.A., 1966, Theoretical analysis of regional analysis flow: 1. Analytical and numerical solutions to the mathematical model. Water Resources Research, 2: 641-656.

Freeze, R. A., Witherspoon, P.A., 1967, Theoretical analysis of regional analysis flow: 2. Effect of water table configuration and subsurface permeability variations. Water Resources Research, 3(2): 623-634

Freeze, R.A., Witherspoon, P.A., 1968, Theoretical analysis of regional analysis flow: 3. Quantitative interpretations. Water Resour. Res., 4(2): 581-590.

Goldberg, E.D., Koide, M., Schmitt, R.A., Smith, R.H., 1963, Rare-Earth Distributions in the Marine Environment: Journal of Geophysical Research, 68-14, 4209-4217.

Gómez-Tuena, A., Orozco-Esquivel, M.T., Ferrari, L., 2007, Igneous petrogenesis of the Trans-Mexican Volcanic Belt: Geological Society of America Special Paper 422, 129-181.

Henderson, P., 1984, General geochemical properties and abundances of the rare earth elements en Henderson, P. (ed.), Rare Earth Element Geochemistry: Developments in Geochemistry, 2, 1-32.

Hernández-Laloth, N., 1991, Modelo conceptual de funcionamiento hidrodinámico del sistema acuífero del Valle de León, Guanajuato: México, DF, México, Universidad Nacional Autónoma de México, Tesis de Licenciatura, 75 pp.

IPLANEG (Instituto de Planeación del Estado de Guanajuato), 2014, Regionalización del Estado de Guanajuato: http://iplaneg.guanajuato. gob.mx, consultado en agosto de 2016

Johannesson, K.H., Stetzenbach, K.J., Hodge V.F., 1997, Rare Earth Elements as Geochemical Tracers of Regional Groundwater Mixing: Geochimica et Cosmochimica Acta, 61(17), 3605-3618.

Johannesson, K.H., Cortés, A., Ramos-Leal, J.A., Ramírez, A.G, Durazo, J., 2005, Geochemistry of Rare Earth Elements in Groundwaters from a Rhyolite Aquifer, Central México en Johannesson, K.H. (ed.), Rare Earth Elements in Groundwater Flow Systems, Water Science and Technology Library: Netherlands, Springer, 51, 187-222.

Kawabe, I., Kitahara, Y., Naito, K., 1991, Non-chondritic yttrium/holmium ratio and lanthanide tetrad effect observed in pre-Cenozoic limestones: Geochemical Journal, 25, 31-44.

Madhavaraju, J., Ramasamy, S., 1999, Rare earth elements in limestones of Kallankurichchi Formation of Ariyalur Group, Tiruchirapalli Cretaceous, Tamil Nadu: Geological Society of India, 54(3), 291-301.

Madhavaraju, J., González-León, C.M., 2012, Depositional conditions and source of rare earth elements in carbonate strata of the Aptian-Albian Mural Formation, Pitaycachi section, northeastern Sonora, Mexico: Revista Mexicana de Ciencias Geológicas, 29(2), 478-49.

Middlesworth, P.E., Wood, S.A., 1998, The aqueous geochemistry of the rare earth elements and yttrium. Part 7. REE, Th and U contents in thermal springs associated with the Idaho batholith: Applied Geochemistry, 13(7), 861-884

Morales-Casique E., Guinzberg-Belmont, J., Ortega-Guerrero M.A., 2016, Regional groundwater flow and geochemical evolution in the Amacuzac River Basin, Mexico: Hydrogeology Journal, 24, 1873-1890. DOI 10.1007/ s10040-016-1423-x.

Mori, L., Gómez-Tuena, A., Cai, Y., Goldstein, S.L., 2007, Effects of prolonged flat subduction on the Miocene magmatic record of the central TransMexican Volcanic Belt: Chemical Geology, 244, 452-473.

Munemoto, T., Ohmori, K., Iwatsuki, T., 2015, Rare earth elements (REE) in deep groundwater from granite and fracture-filling calcite in the Tono area, central Japan: Prediction of REE fractionation in paleo- to presentday groundwater: Chemical Geology, 417, 58-67.

Murray, R.W., Buchholtz ten Brink, M.R., Jones, D.L., Gerlach, D.C., Russ III, G.P., 1990, Rare earth elements as indicators of different marine depositional environments in chert and shale: Geology, 18, 268-271.

Murray, R.W., Buchholtz ten Brink, Gerlach, D.C., M.R., Russ III, G.P., Jones, D.L., 1992, Interoceanic variation in the rare earth, major, and trace element depositional chemistry of chert: Perspectives gained from the DSDP and ODP record: Geochimica et Cosmochimica Acta, 56, 1897-1913.

Nelson, B.J., Wood, S.A., Osiensky, J.L., 2015, Rare earth element geochemistry of groundwater in the Palouse Basin, northern Idaho-eastern Washington: Geochemistry Exploration Environment Analysis, 4, 227-241.

Nieto-Samaniego, Á.F., Alaniz-Álvarez, S.A., Labarthe-Hernández, G., 1997, La deformación cenozoica poslaramídica en la parte meridional de la Mesa Central, México: Revista Mexicana de Ciencias Geológicas, 14(1), 13-25.

Nieto-Samaniego, A.F., Alaniz-Álvarez, S.A., Camprubí, A., 2007, Mesa Central of México: Stratigraphy, structure, and Cenozoic tectonic evolution: Geological Society of America Special Paper 422, 41-70.

Noack, C.W., Dzombak, D.A., Karamalidis, A.K., 2014, Rare Earth Element Distributions and Trends in Natural Waters with a Focus on Groundwater: Environmental Science and Technology, 48, 4317-4326.

Orozco-Esquivel, M.T., Nieto-Samaniego, A.F., Alaniz-Álvarez, S.A., 2002, Origin of rhyolitic lavas in the Mesa Central, Mexico, by crustal melting related to extension: Journal of Volcanology and Geothermal Research, 118, 37-56.

Ortega-Guerrero, M.A., 2000, Estudio hidrogeológico de la Región IV suroeste del Estado de Guanajuato. Informe del convenio de colaboración con el Consejo Regional IV Suroeste del estado de Guanajuato, Primera etapa: México, D.F., Instituto de Geología, Universidad Nacional Autónoma de México, 345 pp.

Ortega-Guerrero, M.A., 2009, Presencia, distribución, hidrogeoquímica y origen 
de arsénico, fluoruro y otros elementos traza disueltos en agua subterránea, a escala de cuenca hidrológica tributaria de Lerma-Chapala, México: Revista Mexicana de Ciencias Geológicas, 26(1), 143-161.

Ortega-Guerrero, A., 2017, Evaporative concentration of arsenic in groundwater: health and environmental implications, La Laguna Region, Mexico: Environmental Geochemistry and Health, 39(5), 987-1003.

Ortega-Guerrero M.A., Farvolden R.N., 1989, Computer analysis of regional groundwater flow and boundary conditions in the Basin of Mexico: Journal of Hydrology. 110, 271-294.

Palmer, C.D., Cherry, J.A., 1984, Geochemical evolution of groundwater in sequences of sedimentary rocks: Journal of Hydrology, 75, 27-65.

Papangelakis, V.G., Moldoveanu, G., 2014, Recovery of rare earth elements from clay minerals en 1st European Rare Earth Resources Conference: Milos, Greece, EURARE Conference Proceedings, 191-202.

Parkhurst, D.L., Appelo C.A.J., 2013, Description of Input and Examples for PHREEQC (Version 3) - A Computer Program for Speciation, Batch-Reaction, One-Dimensional Transport, and Inverse Geochemical Calculations: United States Geological Survey Techniques and Methods, 6(A43), 497 pp. http://pubs.usgs.gov/tm/06/a43.

Piper, D.Z., 1974, Rare earth elements in the sedimentary cycle: a summary: Chemical Geology, 14, 285-304.

R Core Team, 2013, R: A language and environment for statistical computing: Vienn, Austria, R Foundation for Statistical Computing, URL http:// www.r-project.org/, consultado en agosto 2016.

Robertson, F.N., 1989, Arsenic in ground-water under oxidizing conditions, south-west United States: Environmental Geochemistry and Health, 11, 171-185.

Salas, M.A., 2009, Análisis para opciones de manejo de la subcuenca del Río Turbio en el Estado de Guanajuato: México D.F., México, Universidad Nacional Autónoma de México, Instituto de Geofísica, tesis de maestría, $271 \mathrm{p}$.

SGM (Servicio Geológico Mexicano), 1997, Carta Geológico-Minera Estados de Guanajuato (F14-7) y Querétaro (F14-10), escala 1:250,000, México D.F., México, 2 mapas.

Sholkovitz, E.R., Landing, W.M., Lewis, B.L., 1994, Ocean particle chemistry: The fractionation of rare earth elements between suspended particles and seawater: Geochimica et Cosmochimica Acta, 58, 1567-1579.

Siebert, C., Rosenthal, E., Moller, P., Rodiger, T., Meiler, M., 2012, The hydrochemical identification of groundwater flowing to the Bet SheanHarod multiaquifer system (Lower Jordan Valley) by rare earth elements, yttrium, stable isotopes $(\mathrm{H}, \mathrm{O})$ and Tritium: Applied Geochemistry, 27, 703-714.
Sikakwe, G.U., Amah, E.A., Ntekim, E.E.U., Ephraim, B.E., 2016, Environmental Impact and Geochemistry of Rare Earth Elements in Shallow Groundwater from Oban Massif and Environs, Southeastern Nigeria: Journal of Geography, Environment and Earth Science International, 4(4), 1-21.

Smedley, P.L., 1991, The geochemistry of rare earth elements in groundwater from the Carnmenellis area, southwest England: Geochimica et Cosmochimica Acta, 55, 2167-2779.

Spahiu, K., Bruno, J.,1995, A selected thermodynamic database for REE to be used in HLNW performance assessment exercises: Cerdanyola, España, Technical Report MBT Tecnología Ambiental, 91 pp.

Sun, W., McDonough, W.F., 1989, Chemical and Isotopic Systematics of Oceanic Basalts: Implications of Mantle Composition and Processes: London, Geological Society, Special Publications, 42, 313-345.

Tobia, F.H., Aqrawi, A.M., 2016, Geochemistry of rare earth elements in carbonate rocks of the Mirga Mir Formation (Lower Triassic), Kurdistan Region, Iraq: Arabian Journal of Geosciences, 9(4), 259. https://doi. org/10.1007/s12517-015-2148-1.

Tóth, J., 1999, Groundwater as a geologic agent: An overview of the causes, processes, and manifestations: Hydrogeology Journal, 7, 1-14.

Tweed, S.O., Weaver, T.R., Cartwright, I., Schaefer, B., 2006, Behavior of rare earth elements in groundwater during flow and mixing in fractured rock aquifers: An example from the Dandenong Ranges, southeast Australia: Chemical Geology, 234, 291-307.

Webb, G.E., Kamber, B.S., 2000, Rare earth elements in Holocene reefal microbialites: A new shallow seawater proxy: Geochimica et Cosmochimica Acta, 64(9), 1557-1565. https://doi.org/10.1016/S0016-7037(99)00400-7.

Winter J.D., 2014, Chemical Petrology II: Trace Elements and Isotopes en Principles of Igneous and Metamorphic Petrology, Second Edition: Essex, Inglaterra, Pearson New International Edition, 165-190.

Yan, Z., Guijian, L., Sun, R., Tang, Q., Wu, D., Wu, B., Zhou, C., 2013 Geochemistry of rare earth elements in groundwater from the Taiyuan Formation limestone aquifer in the Wolonghu Coal Mine, Anhui province, China: Journal of Geochemical Exploration, 135, 54-62.

Yuan, J., Mao, X., Wang, Y., Deng, Z., Huang, L., 2014, Geochemistry of rareearth elements in shallow groundwater, northeastern Guangdong Province, China: Chinese Journal of Geochemistry, 33, 53-64.

Manuscrito recibido: febrero 7, 2018

Manuscrito corregido recibido: noviembre 23, 2018

Manuscrito aceptado: noviembre 29, 2018 